\title{
Extremes in June rainfall during Indian summer monsoons of 2013 and 2014: Observational Analysis and Extended range prediction
}

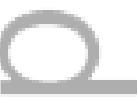

Susmitha Joseph, A. K. Sahai*, R. Chattopadhyay, S. Sharmila, S. Abhilash, M. Rajeevan, R. Mandal, A. Dey, N. Borah and R. Phani

Indian Institute of Tropical Meteorology, Pune, INDIA - 411008

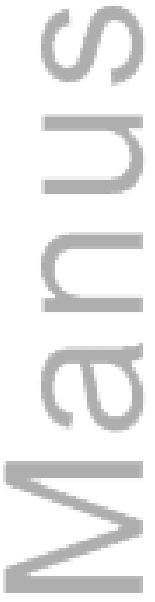

*Corresponding Author Address:

Dr. A. K. Sahai

Indian Institute of Tropical Meteorology

Dr. Homi Bhabha Road

Pashan, Pune - 411 008, India.

E-mail: sahai@tropmet.res.in

$\mathrm{Ph}:+91-20-25904520$

Fax: $+91-20-25865142$

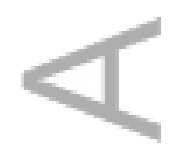

This is the author manuscript accepted for publication and has undergone full peer review but has not been through the copyediting, typesetting, pagination and proofreading process, which may lead to differences between this version and the Version of Record. Please cite this article as doi: $10.1002 / q j .2730$ 


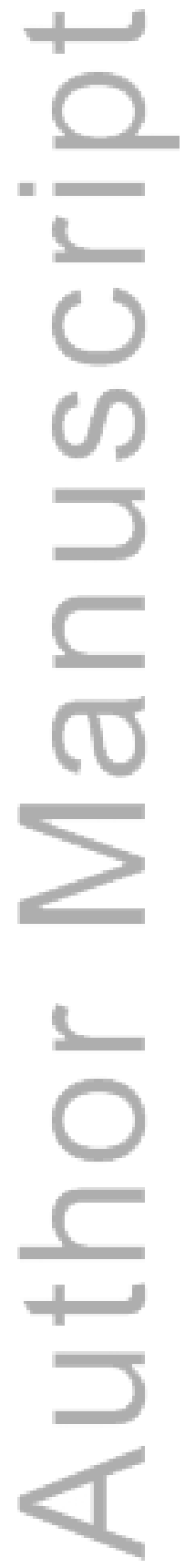

This article is protected by copyright. All rights reserved. 


\section{Abstract}

The onset/progression phase of Indian summer monsoon (ISM) is very crucial for the agricultural sector of the country as it has strong bearing on the sowing of kharif crops, which in turn affects the overall food grain production and hence food security. The recent ISMs of 2013 and 2014 exhibited quite distinct progression phase. While 2013 had one of the fastest advancement in the last 70 years, 2014 witnessed comparatively lethargic progression phase. The major difference was felt in the early monsoon month of June, with 2013 (2014) monthly rainfall being $+34 \%(-43 \%)$ of its long period average. Observational investigations reveal that during June 2013, the monsoon trough was very active in its normal position favouring low level positive vorticity generation and moisture convergence, whereas the absence of monsoon trough facilitated the prevalence of a strong low level anticyclonic circulation over central India during June 2014 hampering the northward progression of ISM. It is found that June 2013 (2014) was associated with (a) stronger (weaker) north-south tropospheric temperature (TT) gradient with positive (negative) TT anomalies over Eurasia and north of $60^{\circ} \mathrm{N}$, (b) colder (warmer) SST anomalies over equatorial Indian Ocean, northwestern Arabian Sea and equatorial eastern Pacific, (c) stronger (weaker) monsoonal Hadley circulation, and (d) stronger (weaker) Walker circulation in response to the colder (warmer) SST anomalies over equatorial Pacific. The study also examines the skill of an Ensemble Prediction System (EPS) in predicting the observed contrasting behaviour during June $2013 / 2014$ on extended range ( $\sim 15-20$ days in advance) in real time. The EPS not only forecasted the observed discrepancy, but also predicted the influential 
role of large scale meteorological conditions that were prevalent during June 2013 (2014), thus advocating the remarkable skill of the EPS in predicting June extremes.

\section{Keywords}

Indian summer monsoon, June extreme, El-Niño, La-Niña, Ensemble Prediction System

\section{Introduction}

$=$ Indian summer monsoon (ISM) is one of the most awaited weather phenomena over the region due to its high socio-economic and hydrological impacts. ISM commences in the month of June over the country and the start of agricultural activities over various parts of the country coincides with the advance of monsoon over the region. As most of the farmlands are rain-fed, monsoon is critical to the food sufficiency and quality of life for the country and is said to be the driver of Indian agriculture (IMD, 2013). Onset phase of monsoon, especially the June rainfall, has strong bearing on the kharif or monsoon crops, which are totally dependent on the rainfall for their growth and development. Therefore, any fluctuations in the spatio-temporal distribution or quantity of the monsoon rains may lead to conditions of floods or droughts causing the agricultural sector to adversely suffer (IMD, 2014), which in turn affect the overall economy, food inflation and therefore the overall quality and cost of living for the general population in India.

In general, monsoon makes its onset over the southern tip of peninsular India around 01 June and progresses northward to cover the entire country by 15 July (Pai and Rajeevan, 2009). However, the onset and progression of monsoon exhibit large amount of interannual variability. In some years they are timely, whereas during some years they are faster or slower. After the 
onset, monsoon advance is not a smooth process but is punctuated by one to three stagnations at different latitudes or longitudes (Sikka, 2011). The stagnations could be caused by the influence of eastward moving upper level westerly troughs in the subtropical latitudes (Biswas et al., 1998) or cessation in the formation of low pressure systems (LPS) in the surrounding seas or within the monsoon trough (Sikka, 2011). During some years, the advancement occurs rapidly and the monsoon covers from Kerala to northwest India in just 15-20 days or so. Similarly, there are years when after a prolonged stagnation in monsoon advance, the next progression of monsoon is quite rapid due to the overlapping formation of LPSs (Sikka, 2011).

The ISMs of 2013 and 2014 were quite distinct in their progression phase. 2013 witnessed the fastest pace of advance of ISM in the last 70 years (IMD, 2013; Joseph et al., 2013, 2014). Monsoon covered the entire country in just 16 days after its onset over Kerala on 01 June, i.e., by 16 June, which is one month ahead of its climatological date. On the other hand, after a delayed onset over Kerala on 06 June, the 2014 monsoon exhibited a sluggish northward progression owing to a prolonged hiatus which occurred after a few days of its onset. Monsoon covered the whole country by 17 July in 2014 .

The major difference in the progression phase during these two years was felt in the early monsoon month of June, in which the long term mean (LTM) monthly rainfall is $163.5 \mathrm{~mm}$ (source: http://www.imdpune.gov.in/mons_monitor/mm_index.html) all over India. The rainfall over the country during the month of June in 2013 was $134 \%$ of its LTM (IMD, 2013), while that of June 2014 was only $56.5 \%$ of its climatology (source: http://www.imdpune.gov.in/mons_monitor/mm_index.html). Although there are other years 
when the June rainfall was $>30 \%$ of its LTM (for e.g., 2001 in the last 14-year period: 20012014; Table 1), June 2013 was exceptional due to its rapid progression phase. The duration of 42 days (as in the case of 2014) is not unusual for monsoon to cover the entire country (please see Table 1), however a deficiency of $\sim 43 \%$ in June rainfall is rather infrequent. Such a dearth was observed recently during 2009, when the June deficit was $\sim 47 \%$.

Joseph et al. $(2013,2014)$ has shown that large scale conditions were very active during June 2013. They argued that the interaction between a monsoonal low pressure system which provided increased low level convergence and abundant moisture, and a midlatitude westerly trough which generated strong upper level divergence has provided conditions conducive for large scale convection and widespread monsoon rains over northwest India. They hypothesized that these large scale conditions helped monsoon to cover the entire country and facilitated the occurrence of the heavy rainfall event in the orographic region of Uttarakhand.

During June 2014, the daily weather bulletins issued by India Meteorological Department (IMD; the official weather forecasting agency under Govt. of India) indicated that the monsoon trough was absent and an anticyclonic circulation was prevalent over central India (CI). This anticyclonic circulation was persistent throughout the month of June, thus delaying the progression of monsoon to the central and northern parts of the country. It affected the agricultural sector adversely by forcing the farmers to shift to short duration varieties; from cash crops to food crops or even fodder (IMD, 2014). According to IMD, a reduction of about 3.67 million tonnes occurred in rice production in 2014 on all India level, compared to 2013. The production of maize also decreased by 1.67 million tonnes (IMD, 2014). On the other hand, the 
significant and well distributed rainfall received during the onset phase of 2013 ISM helped the farmers to sow and transplant the rice and other major crops at the right time in different parts of the country (IMD, 2013).

Considering the above-mentioned impacts of June rainfall on agricultural sector in these two consecutive years, it is worthwhile to explore the underlying mechanisms that shaped the observed discrepancy, and to examine the predictability of the observed contrasting behavior and associated features in the extended range (i.e., 10-20 days in advance) time scale. Although Joseph et al. $(2013,2014)$ provided some insights on the progression of monsoon in 2013, their study focused mainly on the Uttarakhand heavy rainfall event and hence did not provide a detailed study on the background monsoon conditions prevailed during June 2013. Additionally, no detailed documentation is available on the role of meteorological conditions in prevailing the anticyclonic circulation over Indian region during June 2014. Therefore, the present study addresses the following issues: (i) the role of local as well as large scale meteorological conditions that were responsible for the observed fast (slow) progression of monsoon in the month of June 2013 (2014), (ii) whether similar meteorological conditions as that of June 2013 (2014) were existent during June 2001 (2009) when the June rainfall departure was $+35 \%$ (-47\%) and, (iii) whether the observed contrasting behavior was predictable on extended range in real time and if so, whether it helped the farmers to plan their agricultural activities in an efficient way.

The extended range prediction (ERP) group of Indian Institute of Tropical Meteorology (IITM), Pune, India has indigenously developed an Ensemble Prediction System (EPS; Abhilash 
et al., 2012, 2014b; Borah et al., 2013; Sahai et al., 2013) for the prediction of active/break spells of ISM in 2011, under the National Monsoon Mission program (http://www.tropmet.res.in/monsoon/) initiated by the Government of India. The EPS is based on the ocean-atmosphere coupled Climate Forecast System version 2 (CFSv2) model (Saha et al., 2014). The experimental forecasts are available at 5 day interval during the monsoon season from 2001 onwards and are being disseminated at the IITM website http://www.tropmet.res.in/erpas/ on real time basis since 2013. The present study uses the forecasts from this CFSv2 based EPS and details of the EPS is given in the subsequent section (Sec. 2).

\section{Model and Observational datasets}

To assess the predictability aspects, we use the NCEP CFSv2 (Saha et al., 2014), with the Global Forecast System (GFS) as its atmospheric component, coupled to the GFDL Modular Ocean Model version 4p0d (MOM4; Griffies et al., 2004), a four-layer Noah land surface model (Ek et al., 2003) and a two-layer sea ice model (Wu et al., 2005). In this study, the outputs from the multimodel ensemble (MME) generated from the CFSv2 based Grand Ensemble Prediction System (CGEPS; Abhilash et al., 2015a; b) is used. The CGEPS includes three sub-ensembles, from CFSv2 run at T126 ( 100km; hereafter termed as CFS126) and T382 $(\sim 38 \mathrm{~km}$; hereafter termed as CFS382) horizontal resolutions, plus the GFS forced with bias corrected SST from CFS126 (hereafter termed as GFSbc). CGEPS MME has 21 ensemble members of GFSbc and 11 members each of CFS126 and CFS382. Every year, each of these ensembles are run for 45 days lead time every 5 days, starting from 16 May to 28 September. For the experimental details and 
skills of GFSbc, CFS126 and CFS382, refer Abhilash et al. (2012; 2014 a; b) and Sahai et al. (2015) respectively. Each of the ensemble members of the MME are generated by slightly perturbing the initial atmospheric conditions with a random matrix (random number at each grid point) generated from a random seed. In order to center the ensemble seeding around an unperturbed analysis, Gaussian random numbers with mean 0 and unit standard deviation are used to rescale wind, temperature and moisture differences between a short term forecast and its corresponding analysis. It is ensured that amplitude of perturbation varies in accordance with the uncertainty in the analysis. Details on the formulation of EPS can be found in Abhilash et al. (2012, 2014b) and Borah et al. (2013).

For the present study, the observational datasets used are: daily NOAA high resolution Sea Surface Temperature (SST) dataset (Reynolds et al., 2007) provided by the NOAA/OAR/ESRL PSD, Boulder, Colorado, USA, (available at http://www.esrl.noaa.gov/psd/), the daily rainfall dataset from TRMM (Huffman et al., 2007), IMD-TRMM merged rainfall dataset (Mitra et al., 2009) and atmospheric fields from National Center for Environmental Prediction/National Center for Atmospheric Research (NCEP/NCAR) Reanalysis datasets (Kalnay et al., 1996). The meteorological parameters utilized from NCEP/NCAR reanalysis for the study are: zonal, meridional and vertical components of wind, specific humidity, air temperature and geopotential height at pressure levels and also mean sea level pressure (mslp). Additionally, the Moist Static Energy (MSE), Tropospheric Temperature (TT), Kinetic Energy (KE) of total wind as well as rotational wind, velocity potential and divergent wind have been computed. 
The anomalies of various parameters, except rainfall are calculated based on the daily mean climatology of 12 years (2001-2012) for both model as well as observations to maintain commonality and ease of comparison among the datasets.

\section{Results and Discussion}

In this section, we analyze various meteorological parameters which might provide an insight into the local as well as large scale conditions prevalent during June 2013/2014.

\subsection{Observed features during June}

It has been mentioned earlier that the rainfall over the Indian subcontinent was surplus during June 2013, while it was scarce during June 2014; and a low level cyclonic (anticyclonic) circulation was prevalent over the Indian subcontinent during June 2013 (2014). To elucidate this, the rainfall anomaly and $\mathrm{KE}$ of rotational component of $850 \mathrm{hPa}$ wind are plotted and shown in Figure 1 along with the streamlines of total wind anomalies. The figure reveals that during June 2013, the rainfall was largely positive over most parts of the country making it $+34 \%$ of LTM (Figure 1a), while the rainfall was deficient (evident from negative rainfall anomalies) all over the country (-43\% of its LTM) in June 2014 (Figure 1c). Also, the cross equatorial flow was very strong and the monsoon trough was active over CI in June 2013, favoring low level moisture convergence (Figure 1b). During June 2014, the cross equatorial flow was very weak and an intense anomalous anticyclonic circulation was ubiquitous over CI region (Figure 1d). It could be contemplated that the prevalence of this anomalous anticyclonic circulation hindered the northward progression of monsoon in June 2014. The presence of anticyclonic circulation over CI can lead to the suppression of convection over the region, as 
illustrated in Figure 2b that delineates the time-height evolution of anomalous omega (pressure vertical velocity in $\mathrm{hPa} \mathrm{s} \mathrm{s}^{-1}$ multiplied by -1.0 ) over the region $70^{\circ}-85^{\circ} \mathrm{E} ; 15^{\circ}-25^{\circ} \mathrm{N}$. It is appealing that entirely contrasting omega anomalies are noticed over the region during June 2013 and 2014. The descending motion owing to the anticyclonic circulation anomalies at the lower levels (Figure 2b) and the convergence at the upper levels (please refer Figure 4d) has been very strong over the region till first week of July 2014. The contrasting features are further evident in Figure 2c and d, that portrays the monsoonal Hadley circulation during June. During June 2013, the monsoonal Hadley circulation, which is generally characterized with ascending motion over Indian subcontinent and descending motion over the south equatorial Indian Ocean, was very strong (Figure 2c). In the case of June 2014, strong anomalous subsidence (which is associated with the anticyclone over the region) prevailed over the Indian region while anomalous upward motion was noticed south of the equator (Figure 2d). Thus the atmosphere was very unstable (stable) over the Indian region during June 2013 (2014).

Large-scale organized convection, such as the ISM rainfall, is associated with reduced vertical static stability. The MSE of the surface layer is a useful measure of vertical instability and is defined as:

$$
M S E=C_{p} T+g z+L_{c} q
$$

where, the first two terms on the RHS represents the dry static energy and the third term represents the moisture term. Chakraborty et al. (2006) showed that the convective available potential energy (CAPE) becomes positive and increases rapidly only after the surface MSE reaches a threshold value of $346 \mathrm{~kJ} / \mathrm{kg}$. It is found that during June 2013, the MSE values over CI 
region $\left(70^{\circ}-85^{\circ} \mathrm{E} ; 15^{\circ}-25^{\circ} \mathrm{N}\right)$ are always above the threshold value, whereas they are mostly below the threshold value during June 2014 (Figure not shown). The spatial patterns of MSE anomalies during June 2013 and 2014 are shown in Figures 3a and $\mathbf{c}$ respectively. The figure clearly-brings out the asymmetry in these two years. During June 2013, the anomalies are largely positive over most parts of the country, whereas the anomalies are negative over CI during June 2014. It is evident from the figure that enormous amount of instability was existent during June 2013, compared to 2014, which might have helped monsoon to cover the entire country in a faster pace during 2013. The vertically integrated (from surface to $500 \mathrm{hPa}$ level) moisture anomalies during June 2013 and 2014 are shown plotted in Figures 3b and d respectively. The positive (negative) precipitable water anomalies are noticed during June 2013 (2014), which could be attributed to the fact that the moisture term is the major contributor in the MSE equation (Chakraborty et al., 2006). Both the negative MSE and moisture anomalies are indicative of the presence of a stable atmosphere over CI during June 2014 that might have contributed to the hiatus in the northward progression of monsoon observed during the period.

From the above discussion, it could be speculated that the preponderance of the anomalous anticyclonic circulation and the absence of monsoon trough at low level has inhibited the northward progression of monsoon in June 2014. Presence of such anomalous anticyclonic circulation over $\mathrm{CI}$ is generally observed during typical break monsoon periods (Krishnan et al., 2000; Joseph et al., 2009 among others). The northward advancement of monsoon was favored only after the dissipation of the anticyclonic circulation, with the establishment of monsoon 
trough. Thus, the analyses raise an interesting question - what caused the prevalence of these observed features? This will be addressed in the forthcoming section of the paper.

\subsection{Large scale influence on the observed disparity}

\subsubsection{Global SST}

Suppressed (enhanced) convection over Indian region is known to be related to the warmer (colder) SST anomalies over equatorial Indo-Pacific oceanic regions (Ashok et al., 2012; Meehl, 1987; Rao and Goswami, 1998; Rajeevan and McPhaden, 2004 among others). Hence SST anomalies over the Indo-Pacific region during June 2013 and 2014 have been plotted and shown in Figure 4a and $\mathbf{b}$. It is remarkable to note that cold (warm) anomalies indicative of LaNiña (El-Niño) conditions are noticed over the equatorial eastern Pacific during June 2013 (2014). In conjunction with the cold (warm) SST anomalies over the equatorial Pacific, negative (positive) rainfall anomalies are observed over the region during June 2013 (2014) (Figure not shown). Rainfall anomalies of opposite polarity to that of equatorial Pacific Ocean are seen over Indian subcontinent, indicating their out-of-phase relationship. In the case of June 2013, the weak La-Niña conditions and associated upper level convergence (Figure 4c) in the eastern Pacific could have intensified the Walker circulation (Figure 4e) that is favorable for monsoon rains over India through modulation of monsoonal Hadley circulation. Interestingly, the warm anomalies extend across the equatorial Pacific during June 2014 exhibiting a basin wide warming signature (Figure 4b). It is noted that the warming was ubiquitous over the region in the pre-monsoon months also (Figure not shown). Such basin wide warming can lead to suppressed convection over Indian region as in the case of June 2009 (Ratnam et al., 2010; 
Ashok et al., 2012) when the June rainfall departure over the country was $-47 \%$. In conjunction with this basin wide warming, anomalous upward motion is observed almost everywhere in the tropical Pacific (Figure 4f). This is indicative of the anomalously weak Walker circulation over the region. It is found that the anomalous outflow of divergent wind over the central and eastern equatorial Pacific region, which is associated with the convection due to warm SST anomalies over the region, has an anomalous subsiding branch over the Indian subcontinent (Figure 4d). This is a typical El-Niño effect (Annamalai, 2010; Slingo and Annamalai, 2000) and similar conditions were prevalent over the Indo-Pacific region during 2009 (Ratnam et al., 2010). Joseph et al. (1994) and Ju and Slingo (1995) suggested that years with warm SST anomalies in the equatorial central and east Pacific Ocean have a weaker monsoon circulation and a delayed onset. Thus it can be envisaged that although some studies claim that the ENSO-monsoon relationship has weakened (for e.g., Kumar et al., 1999), the influence of equatorial Pacific Ocean on the ISM remains relevant even in the recent times, as evident in June 2014.

Another important disparity noticed during June 2013 (2014) is the presence of cold (warm) SST anomalies over northwestern Arabian Sea (AS) (please refer Figure 4a and b). Such anomalous warming (cooling) in the northwestern AS is unfavorable (favorable) for monsoon activity over Indian subcontinent (Ramesh and Krishnan, 2005; Li and Yanai, 1996). The warm SSTs over the region during June 2014 seems to be generated by the weak monsoonal westerly winds (see Figure 1d) which in turn contributed to the reduced upwelling and hence inhibited the cooling in the northwestern AS. On the contrary, the strong monsoonal currents during June 2013 might have led to strong upwelling and thereby contributed to cooling in the northern AS. 
The warming (cooling) over northwestern AS during June 2014 (2013) is noticed during June 2009 (2001) also (Suppl. Figure S1).

It is to be noted that the warm anomalies during June 2014 preponderated all-across the Indian Ocean (Figure 4b), suggesting a basin wide warming. The warming was evident even in the pre-monsoon months (Figure not shown). Joseph et al. (1994) suggested that the existence of such warm SST anomalies over the equatorial Indian Ocean can adversely affect the ISM strength by delaying its onset and advancement. They also hypothesized that such delay in the onset and advancement of ISM associated with the Indian Ocean warm SSTs is more pronounced during the onset phase of El-Niño, as experienced in June 2014.

\subsubsection{Tropospheric Temperature}

It is well-known that the seasonal heating of the elevated surface of the Tibetan Plateau, and the consequent reversal of tropospheric temperature (TT; defined as air temperature averaged between 600 and $200 \mathrm{hPa}$ by Xavier et al., 2007) along with the pressure gradients south of $35^{\circ} \mathrm{N}$, trigger the large-scale change in the general circulation over Asia and the abrupt burst of the monsoon over the Indian subcontinent (Flohn, 1960; Xavier et al., 2007). The strength of the ISM is closely related to the sign of the meridional gradient of TT (defined by Xavier et al., 2007 as the difference of TT values between the northern box $40^{\circ}-100^{\circ} \mathrm{E} ; 5^{\circ}-35^{\circ} \mathrm{N}$ and the southern box $\left.40^{\circ}-100^{\circ} \mathrm{E} ; 15^{\circ} \mathrm{S}-5^{\circ} \mathrm{N}\right)$. Therefore, the TT gradient during 2013 and 2014 is plotted in Figure 5. It is worthwhile to note that the TT gradient during 2013 is well above climatology from second half of May onwards. Conversely during 2014, the gradient is well below the climatology till second half of June, and it became positive from negative by 06 June 
(the date on which monsoon onset over Kerala occurred). The large values of TT gradient during 2013 could be attributed to the warm TT anomalies present in the northern hemisphere, compared to the south of equator (Suppl. Figure S2a). It is important to note that the TT anomalies are warmer in the equatorial region during 2014 compared to 2013 (Suppl. Figure S2b). Hence it could be concluded that it is the north-south gradient of TT, rather than the actual TT values, that are critical in modulating the strength of ISM.

Xavier et al. (2007) indicated that the warmer SSTs over equatorial Pacific Ocean during El-Niño years can regulate the ISM strength through the atmospheric response to the diabatic heating associated with the SST, leading to a substantial reduction of the meridional gradient of TT over the Indian monsoon region and this is evident in June 2014. The converse is true for LaNiña years. They also advocated that the negative TT anomaly over Eurasia during pre-monsoon months forced by El-Niño heating delays the onset of ISM. The January-May averaged TT anomalies during 2013 and 2014 have been plotted in Suppl. Figure S2c and d respectively. Interestingly, negative TT anomalies are seen over Eurasian region during 2014 (Suppl. Figure S2d). This cooling signature is evident in the monthly averaged TT anomalies plotted for individual months from January-May (Figure not shown). The negative TT anomalies preponderate over the midlatitudes even during June 2014 (Suppl. Figure S2b). This proved to be detrimental for the monsoon activity over Indian subcontinent. As suggested by Xavier et al. (2007), these negative TT anomalies over Eurasia in the pre-monsoon months as well as in June might have weakened the north-south TT gradient, thereby delaying the onset of 2014 monsoon and weakening the monsoon activity during June. These weakened TT gradients could also be 
attributed to the warming in the tropical Pacific during premonsoon months (Figure not shown). In contrast, the anomalously warmer TT anomalies over Eurasian region supported the enhancement of monsoon activity over Indian region during June 2013.

The strengthened (weakened) TT gradients observed during June 2013 (2014) were noticed during June 2001 (2009) also (Suppl. Figure S3).

\subsubsection{Midlatitude Influence}

As the monsoon sets in and progresses, the subtropical westerlies in the upper troposphere move northward away from the Indian region and the tropical easterlies dominate over the region. However, at times, these upper tropospheric westerlies associated with the midlatitude weather systems (like troughs) intrude southwards to the Indian region and affect the ISM. They can adversely affect the ISM by causing break-like conditions over Indian region (Ramaswamy, 1962; Krishnan et al., 2009). Krishnamurti et al. (2010) showed that the intrusion of westerlies associated with the midlatitude troughs and the associated cold air advection was instrumental in generating the subdued convective activity over the Indian region during June 2009. It has been noted from the previous sections that June 2014 share some commonality with June 2009. Hence, we plotted the zonal component of $200 \mathrm{hPa}$ wind along with its magnitude in Figure 6 for a period of 10 days each (i.e., 01-10 June, 11-20 June and 21-30 June). The prevalence of midlatitude westerlies over Indian region is evident during almost whole of June 2014. Interestingly, the intrusion is noticed during 2013 from 11-20 June. The heavy rainfall event over Uttarakhand occurred in concurrence with this intrusion. Joseph et al. $(2013,2014)$ indicated that the interaction between the midlatitude westerly trough and a monsoonal low 
pressure system played seminal role in generating this extreme event over the orographic region. They hypothesized that the low pressure system provided huge amount of moisture to the region and the westerly trough intrusion has instigated the heavy rainfall event in the moist environment, as suggested by $\mathrm{Li}$ and $\mathrm{Fu}$ (2006). Thus it is found that the same meteorological condition, i.e., the midlatitude westerly intrusion, has forced the generation of contrasting phenomena over Indian region during June 2013 and 2014. This finding supports the theory proposed by Sikka (2011). According to his study, the interaction between ISM and the upper tropospheric westerlies associated with the midlatitude troughs and its influence on the ISM depends upon the status of the monsoon activity at the time of beginning of interaction period and also the phase of the Rossby wave. The study proposed that if the monsoon is in its weakening phase, the approach of a westerly trough would aggravate 'break conditions' in the monsoon, while if the monsoon is in intensifying stage, such interaction would result in enhancement of rainfall over Indian subcontinent. During June 2013, the background moisture was ample (as evident from Figure 3b) whilst dry conditions were prevalent over most parts of the country during June 2014 (Figure 3d). Therefore, it could be contemplated the midlatitude westerly intrusion intensified the active (break) situations during June 2013 (2014), as suggested by Sikka (2011).

The westerly trough incursions during June 2014 could be attributed to the El-Niño conditions that were developing in the Pacific (Krishnan et al., 1998; Hoskins and Wang, 2005) or to the recent increasing Arctic Amplification (Screen and Simmonds, 2010; Pithan and Mauritsen, 2014). Both of these factors can induce north-south meandering of subtropical 
westerly jetstreams, which in turn cause the troughs embedded in the westerlies to intrude southwards to the tropical region affecting the tropical climate.

\subsection{Extended Range Prediction of the observed disparity}

In Sec. 3.2, the observed local as well as large scale features during June 2013 and 2014 have been discussed and it is found that the contrasting rainfall could be framed by the large scale warming in the tropical Pacific together with the midlatitude influence, which might also be linked to the Pacific warming to some extent. Now, it is worthy to examine whether this contrasting behaviour had some predictability on extended range. As mentioned earlier, the CGEPS MME used in this study has been employed to generate the real-time experimental extended range forecasts during 2013 and 2014 ISMs, and Borah et al., (2014) and Sahai et al., (2015) has shown that the MME could reasonably predict the intraseasonal variations during 2013 and 2014 ISMs respectively. However, these studies analysed the general proficiency of the MME in predicting the ISMs with emphasis to selected active/break spells, and did not study the June extremes. Therefore, the skill of the CGEPS MME in predicting the contrasting progression phase of ISM and the observed June extremes during 2013 and 2014 has been evaluated here.

Prior to this evaluation, it is advisable to examine the ability of the MME in predicting June extremes in general. As mentioned in Table-1, there are 4 cases of June extremes during 2001-14. In 2001 and 2013, the June rainfall was exceptionally positive $(+35.6 \%$ and $+34.4 \%$ respectively); whereas, the June rainfall was remarkably negative during 2009 and 2014 (-47.2\% and $-43.5 \%$ correspondingly). Figure 7 depicts the pentad-wise percentage departure of rainfall over monsoon zone (defined by Rajeevan et al., 2010) for observation as well as the prediction in 
pentad 1 to pentad 4 (P1-P4; 05-20 day) lead times. It is worthwhile to note that the CFSv2 based MME could predict the extremes of June rainfall in almost all pentad leads with great fidelity. This gives us the confidence to use this MME for the detailed study of contrasting progression phase of ISM during June 2013 and 2014.

\subsubsection{Predicted features during June 2013 and 2014}

Figure 8 depicts the predicted rainfall anomalies and low level $(850 \mathrm{hPa})$ wind along with the KE of its rotational component, from P1-P4 pentad leads. It is clear from Figure 8a-h that the MME could predict the contrasting June rainfall anomalies during 2013 and 2014 convincingly in all the pentad leads, albeit the anomalies weaken with increasing lead. Figure 8ip exhibits the KE of rotational component of $850 \mathrm{hPa}$ wind along with the streamlines of total wind anomalies. The strengthened (weakened) cross equatorial flow during June 2013 (2014) was predicted by the MME in all the pentad leads. Although the cyclonic (anticyclonic) circulation is well defined in observations during 2013 (2014), it is not distinct in MME. However, the inflow towards (outflow from) central Indian region is clear in MME. This becomes discernible in Figure 9a-h that shows the time-height evolution of anomalous omega (pressure vertical velocity in $\mathrm{hPa} \mathrm{s}{ }^{-1}$ multiplied by -1.0 ) over the CI region $70^{\circ}-85^{\circ} \mathrm{E} ; 15^{\circ}-25^{\circ} \mathrm{N}$. It is appealing that entirely contrasting omega anomalies noticed over the region in observations during June 2013 and 2014 (Figure 2a and b) are forecasted by the MME realistically in almost all pentad leads. The ascending motion corresponding to the cyclonic circulation anomalies during June 2013 is forecasted by the MME in P1-P4 pentad leads (Figure 9a-d). Moreover, the descending motion over central India associated with the anticyclonic circulation anomalies 
during June 2014 is predicted at all pentad leads realistically (Figure 9e-h). Similar results are seen in Figure 9i-p that depicts the monsoonal Hadley circulation during June 2013/14. During June 2013, the monsoonal Hadley circulation, which is generally characterized with ascending motion over Indian subcontinent and descending motion over the south equatorial Indian Ocean, was very strong (Figure 2c). In the case of June 2014, strong anomalous subsidence (which is associated with the anticyclone over the region) prevailed over the Indian region while anomalous upward motion was noticed south of the equator (Figure 2d). It is interesting to note that these contrasting features during June 2013 and 2014 are well predicted by the MME up to fourth pentad lead (Figure 9i-p).

It is clear from this subsection that the MME based on CFSv2 could realistically predict the observed features during June 2013 and 2014. It is shown in Sec. 3.2 that these observed contrasting features were governed by large scale meteorological conditions. In the forthcoming subsection, we examine whether the MME could predict the influential role of large scale conditions correctly.

\subsubsection{Role of large scale conditions as predicted by the MME}

It is found in Figure 4 that anomalous inflow (outflow) of divergent wind was existent over the equatorial eastern Pacific during June 2013 (2014) in response with the cold (warm) anomalies indicative of La-Niña (El-Niño) conditions over the region. It is seen that the MME could predict the anomalous inflow over the central Pacific in response to the low level divergence in the region in the first two pentads, but failed to predict the inflow over eastern Pacific during June 2013(Figure 10a-d). At longer leads, the inflow over eastern Pacific was 
predicted to some extent. Altogether, the response of the MME to the cooler event in the Pacific is quite different from the observation. On the other hand, it could predict the anomalous outflow associated with the low level convergence during June 2014, at all pentad leads (Figure 10e-h). This indicates that the MME could predict the anomalous warming of equatorial Pacific during June 2014 in advance, indicating the skewness of the MME to the El-Niño events. This becomes more discernible in Figure 10m-p that shows the strong upward motion over the equatorial Pacific during June 2014 suggestive of weakened Walker circulation. The Walker circulation response of the MME during June 2013 is is quite distinct from the observations.

Another important characteristic noticed during June 2013 (2014) was the stronger (weaker) TT gradient (Figure 5). It is interesting to note that even with inherent cold bias in temperature, the MME could predict this disparity with great fidelity (Figure 11) in all the pentad leads. It is also found that the strong (weak) TT values to the north of the equator during June 2013 (2014) are predicted by the MME from P1 to P4 leads (Suppl. Figure S4).

It has been shown in Sec. 3.2.3 and Figure 6 that southward incursion of troughs embedded in the midlatitude westerlies affected the monsoon activity during June 2013 and 2014 in a different way. In June 2013, when the monsoon was in intensifying stage, the interaction helped in the enhancement of rainfall over Indian subcontinent, while in June 2014 when the monsoon was in weakening phase, the approach of the westerly trough intensified the "break conditions' in the monsoon. The midlatitude westerly intrusion and the associated vigorous ISM activity was noticed in mid June in concurrence with the Uttarakhand heavy rainfall event and hence we examined the midlatitude influence on the ISM activity in a period of 10 days each in 
Figure 6. Therefore, we assessed the skill of the MME in predicting the midlatitude influence in the same way and shown plotted in Figure 12 as four subpanels for P1 to P4 lead times (Figures 12a-f, 12g-l, 12m-r and 12s-x are for P1, P2, P3 and P4 lead times respectively). The southward intrusion of midlatitude westerlies during June 2014 has been predicted by the MME in all the pentad leads; however, the intrusion during 11-20 June 2013, which was instrumental in generating the Uttarakhand event, is not predicted by the MME, except at P1 lead (Figure 12).

Thus, it is apparent from this subsection that the large scale meteorological conditions that were observed during the contrasting June extremes during 2013/14, especially 2014 were predicted reasonably by the MME. It is thus ensured that the MME could predict the observed disparity for the right reasons.

\section{Conclusions}

The present study investigates the scientific rationale as well as the predictability aspects of the observed contrasting progression phase of ISM during 2013 and 2014, with special emphasis on the disparity noticed in the early monsoon month of June. It is identified that during June 2013, the cross equatorial flow was very strong and brought ample amount of moisture to the Indian region, favoring low level moisture convergence and prevalence of positive MSE anomalies (which is indicative of large scale instability) over the region. The weak La-Niña conditions over eastern equatorial Pacific, warmer SSTs over western AS and warmer TT anomalies over the Eurasian region also provided an environment that is conducive for large scale convection over the Indian region. Additionally, a midlatitude westerly trough interacted with a monsoonal low pressure system in this highly unstable environment around 16 June 
(Joseph et al., 2013, 2014). These large scale conditions helped monsoon to cover the entire country by 16 June. In contrast, during June 2014 , the cross-equatorial flow was weak owing to weak north-south gradient of TT. The weak TT gradients could be ascribed to the colder TT anomalies over Eurasia and warmer troposphere over equatorial regions. The reduction of the meridional gradient of TT over the Indian monsoon region might also be related to the atmospheric response associated with the basin wide warming noticed in the equatorial Pacific in the pre-monsoon months and June. The warmer SSTs over the equatorial Indian Ocean and western AS also proved to be fatal for the ISM activity in June. Moreover, the pervasiveness of midlatitude westerlies over the Indian region (which is unfavorable for ISM activity) was noticed during June 2014. All these factors contributed to the existence of negative MSE anomalies over the Indian region, which subsequently favored the absence of monsoon trough and the formation as well as the sustenance of anticyclonic circulation over CI region.

Now there remains an interesting question - what caused the increased wave activity in the midlatitudes during 2014, which in turn made the midlatitudes colder and contributed to the weakening of meridional TT gradient? A recent study by Coumou et al. (2014) provided evidences for the weakening of the zonal mean midlatitude westerly jets and an amplification of quasi-stationary waves by resonance between free and forced waves in the midlatitude waveguides, in the recent decade. They argued that the rapid warming in the Arctic during the past few decades (termed as Arctic Amplification; Screen and Simmonds, 2010; Pithan and Mauritsen, 2014, among others) and associated changes in the zonal mean zonal wind have created favorable conditions for double jet formation in the extratropics, which promotes the 
development of resonant flow regimes (i.e., larger north-south meanders in the flow) over the region. As this meandering develops, troughs may be expected to extend further southwards bringing in cold polar air to the tropics and ridges push the warm tropical air further northwards. The southward penetration of these troughs to the tropical regions can cause the mid-latitude weather systems to be more persistent (Francis and Vavrus, 2012; Cohen et al. 2014; Coumou et al., 2014; Francis and Skific, 2015) and can modulate the ISM activity significantly. However, the manner in which this interaction modulates the ISM activity depends upon the background conditions prevailing over the Indian region at the time of interaction (Sikka, 2011), as noticed during June 2013 and 2014.

Krishnan et al. (1998) and Hoskins and Wang (2005) indicated that large-scale tropical heating such as El-Niño can support the generation of stationary Rossby waves in the midlatitudes through Rossby wave dispersion from tropics to midlatitudes. During El Nino events, polar jet stream diverges from its usual path and more mid-latitude westerly troughs move across north India. The southward penetration of these midlatitude waves may lead to cold air incursion into the tropical domain. It was noted from Figure $\mathbf{4 b}$ that El-Niño conditions were prevalent in the equatorial tropical Pacific during June 2014. Hence it could be envisaged that the SST anomalies also might have contributed to the increased wave activity in the midlatitudes.

It is to be noted that the large scale conditions observed during June 2013 (2014) share some commonality with those during June 2001 (2009), when the rainfall departure for the month was $+35 \%$ (-47\% ). During both June 2001 and 2013, the weak La-Niña conditions were prevailing over eastern equatorial Pacific (refer Figure 4a and Suppl. Figure S1). Moreover, the 
TT gradients were very strong (well above climatology) from second half of May onwards during both these years (Figure 5 and Suppl. Figure S3). Regarding June 2009 and 2014, both the years witnessed a basin wide warming over the equatorial Indo-Pacific Oceans (refer Figure 4b and Suppl. Figure S1), which in turn weakened the ISM activity over Indian region through slackening of the equatorial Walker circulation and subsequent modulation of the monsoon Hadley circulation. The warmer SSTs also contributed to the weakening of meridional TT gradient in these two years (see Figure 5 and Suppl. Figure S3). During both June 2009 and 2014, the southward incursion of troughs embedded in the midlatitude westerlies was identified (please refer Krishnamurti et al., 2010 and Figure 6). This westerly incursion also favored the decreased monsoon activity during June 2009 and 2014. An interesting question that arises from the above analysis is on the relative contribution of the tropical and midlatitude forcings in governing the contrasting June rainfall during June 2013/14. There are evidences in the literature that tropical forcing can modulate the extratropical atmosphere (e.g., Krishnan et al., 1998), which in turn affects the tropical atmosphere. Additionally, the extratropical weather systems can influence the tropical atmosphere on their own. Assessing the relative role of these forcings require experiments using idealized models and this is beyond the scope of the present study.

The skill of a CFSv2 based MME is also examined in predicting the observed discrepancy in June rainfall, on extended range. It is found that MME has remarkable skill in predicting June extremes and it could predict the contrasting behavior during June 2013/2014 in almost all pentad (P1-P4) leads. It not only predicted the observed difference in rainfall and wind circulation anomalies over the Indian region (Figure 8), but also reasonably predicted the 
influential role of large scale meteorological conditions such as the El-Niño/La-Niña over equatorial Pacific, the TT gradients and the midlatitude influence, on the events (Figures 10-12).

The experimental extended range forecasts generated by IITM were disseminated at the IITM website since 2013, and these were used by IMD for generating agrometeorological advisory bulletins during 2013 and 2014 ISMs. These bulletins proved to be very useful to the farmers in planning agricultural operations well in advance by decreasing the vulnerability of agriculture to increasing climatic variability and thus increase the crop production during 2014, without putting additional stress on natural environment and also to manage the cost of cultivation (IMD, 2014). On the other hand, the reduced monsoon activity during June 2009 resulted in the rice and other kharif crop loss was significant with rice production declining by 20.7 million tons from the previous year's levels (source: Gain report of USDA Foreign Agricultural Service available at http://www.tropmet.res.in/ kolli/MOL/Links/agri-impact.pdf). If these forecasts were available during 2009 monsoon season, the advisories would have been given to the farmers in the right time and hence the crop loss would have been reduced to some extent. This study thus advocates the usefulness and suitability of the MME based on CFSv2 in the prediction of ISM variability on extended range and applications in agricultural planning.

\section{Acknowledgements}

IITM is fully supported by the Ministry of Earth Sciences, Govt. of India. The authors gratefully acknowledge the reviewers for their constructive and insightful comments that helped considerably in improving the manuscript. The model runs are carried out on Prithvi IBM High 
Performance Computing System installed at IITM, Pune. The figures in this paper are generated using GrADS and Xmgrace.

\section{References}

Abhilash S, Joseph S, Chattopadhyay R, Pattnaik S, Krishna RPM, De S, Sahai AK, Goswami BN. 2012. Performance of an Ensemble Prediction System based on CFSV2 for the Extended Range Prediction of Active-Break Spells of Indian Summer Monsoon Rainfall during 2011. IITM Res. Rep. RR-128. December 2012. ISSN 0252-1075.

Abhilash S, Sahai AK, Borah N, Chattopadhyay R, Joseph S, Sharmila S, De S, Goswami BN. 2014a. Does bias correction in the forecasted SST improve the extended range prediction skill of active-break spells of Indian summer monsoon rainfall? Atmos. Sci. Lett. 15: 114119. DOI:10.1002/as 12.477

Abhilash S, Sahai AK, Borah N, Joseph S, Chattopadhyay R, Sharmila S, Rajeevan M, Mapes BE, Kumar A. 2015a. Improved Spread-Error Relationship and Probabilistic Prediction from CFS based Grand Ensemble Prediction System. J. Appl. Met. Climatol. DOI: 10.1175/JAMC-D-14-0200.1.

Abhilash S, Sahai AK, Borah N, Joseph S, Chattopadhyay R, Sharmila S, Rajeevan M, Mapes BE, Kumar A. 2015b. Bull. Amer. Met. Soc.

Abhilash S, Sahai AK, Pattnaik S, Goswami BN, Kumar A. 2014b. Extended Range Prediction of Active-Break Spells of Indian Summer Monsoon Rainfall using an Ensemble Prediction System in NCEP Climate Forecast System. Int. J. Climatol. 34: 98-113. DOI: 511 10.1002/joc. 3668 
Annamalai H. 2010. Moist Dynamical Linkage between the Equatorial Indian Ocean and the

South Asian Monsoon Trough. J. Atmos. Sci. 67:589-610. doi: http://dx.doi.org/10.1175/2009JAS2991.1

Ashok K, Sabin TP, Swapna P, Murtugudde RG. 2012. Is a global warming signature emerging in the tropical Pacific? Geophys. Res. Lett. 39: L02701. doi: :10.1029/2011GL050232

Biswas NC, De US, Sikka DR. 1998. The role of Himalayan massif - Tibetan Plateau and the mid-tropospheric tropical ridge over north India during the advance phase of the southwest monsoon. Mausam. 49: 285-293

Borah N, Abhilash S, Joseph S, Chattopadhyay R, Sharmila S, Sahai AK. 2013. Development of extended range prediction system using CFSv2 and its verification. IITM Res. Rep. RR130. ISSN 0252-1075

Borah N, Sahai AK, Abhilash S, Chattopadhyay R, Joseph S, Sharmila S, Kumar A. 2014. An assessment of real-time extended range forecast of 2013 Indian summer monsoon. Int. J. Climatol. doi: 10.1002/joc.4178

Chakraborty A, Nanjundiah RS, Srinivasan J. 2006. Theoretical aspects of the onset of Indian summer monsoon from perturbed orography simulations in a GCM. Ann. Geophys. 24: 2075-2089

Cohen J, Screen JA, Furtado JC, Barlow M, Whittleston D, Coumou D, Francis JA, Dethloff K, Entekhabi D, Overland J, Jones J. 2014. Recent Arctic amplification and extreme mid-latitude weather. Nat. Geo. DOI: 10.1038/NGEO2234 
Coumou D, Petoukhov V, Rahmstorf S, Petri S, Schellnhuber HJ. 2014. Quasi-resonant circulation regimes and hemispheric synchronization of extreme weather in boreal summer. $P N A S$. www.pnas.org/cgi/doi/10.1073/pnas.1412797111

Ek M, Mitchell K, Lin Y, Rogers E, Grunmann P, Koren V, Gayno G, Tarpley J. 2003. Implementation of Noah land surface model advances in the National centers for environmental prediction operational mesoscale Eta model. J. Geophys. Res. 108(D22):8851

Flohn H. 1960 Recent investigations on the mechanisms of the "summer monsoon" of southern and eastern India. Monsoons of the World. India Meteorological Department: New Delhi. India. $75-88$.

Francis J, Skific N. 2015. Evidence linking rapid Arctic warming to mid-latitude weather patterns. Phil. Trans. R. Soc. A 373: 20140170. http://dx.doi.org/10.1098/rsta.2014.0170

Francis JA, Vavrus SJ. 2012. Evidence linking Arctic amplification to extreme weather in midlatituides. Geophys. Res. Lett. 39: L06801. doi:10.1029/2012GL051000

Griffies SM, Harrison MJ, Pacanowski RC, Rosati A. 2004. A Technical Guide to MOM4. GFDL Ocean Group Technical Report. No 5. Princeton NJ NOAA/Geophysical Fluid Dynamics Laboratory $342 \mathrm{pp}$

Hoskins BJ, Wang B. 2005. Large scale atmospheric dynamics. The Asian Monsoon Ed Wang B Chapt 9. 357-415. Springer New York 
Huffman GJ, Adler RF, Bolvin DT, Gu G, Nelkin EJ, Bowman KP, Hong Y, Stocker EF, Wolff DB. 2007. The TRMM Multi-satellite Precipitation Analysis: Quasi-Global, Multi-Year, Combined-Sensor Precipitation Estimates at Fine Scale. J. Hydrometeor. 8(1): 38-55 IMD. 2013. Monsoon 2013: A Report. IMD Met Monograph. No.: ESSO/IMD/SYNOPTIC MET/01-2014/15. India Met Department Eds Pai DS and Bhan SC available at $=$ http://www.imdpune.gov.in/

IMD. 2014. Monsoon 2014: A Report. IMD Met Monograph. No.: ESSO/IMD/Synoptic Met./01(2015)/17. India Met Department Eds Pai DS and Bhan SC available at http://www.imdpune.gov.in/

Joseph PV, Eischeid JK, Pyle RJ. 1994. Interannual variability of the onset of the Indian summer monsoon and its association with atmospheric features, El-Niño, and sea surface temperature anomalies. J. Clim. 7: 81-105.

Joseph S, Sahai AK, Goswami BN. 2009. Eastward propagating MJO during boreal summer and Indian monsoon droughts. Clim. Dyn. 32:1139-1153 DOI:10.1007/s00382-008-0412-8

Joseph S, Sahai AK, Sharmila S, Abhilash S, Borah N, Chattopadhyay R, Pillai PA, Rajeevan M, Kumar A. 2014. North Indian heavy rainfall event during June 2013: diagnostics and extended range prediction. Clim. Dyn. DOI 10.1007/s00382-014-2291-5 published online 19 August 2014.

Joseph S, Sahai AK, Sharmila S, Abhilash S, Borah N, Pillai PA, Chattopadhyay R, Kumar A. 2013. Extended Range Prediction of Uttarakhand Heavy Rainfall Event by an Ensemble 
Prediction System based on CFSv2. IITM Res. Rep. ISSN 0252-1075 ESSO/IITM/SERP/SR/03(2013)/180

Ju J, Slingo J. 1995. The Asian summer monsoon and ENSO. Quart. J. Roy. Met. Soc. 121: 1133-1168

Kalnay E, co-authors. 1996. The NCEP/NCAR 40-year reanalysis project. Bull. Amer. Met. Soc. 77 doi:10.1175/1520-0477

Krishnamurti TN, Thomas A, Simon A, Kumar V. 2010. Desert Air Incursions, an Overlooked Aspect, for the Dry Spells of the Indian Summer Monsoon. J. Atmos. Sci. 67: 3423-3441

Krishnan R, Kumar V, Sugi M, Yoshimura J. 2009. Internal feedbacks from monsoonmidlatitude interactions during droughts in the Indian summer monsoon. J. Atmos. Sci. $66: 553-578$

Krishnan R, Venkatesan C, Keshavamurty RN. 1998. Dynamics of upper tropospheric stationary wave anomalies induced by ENSO during the northern summer, a GCM study. Proc. Ind. Acad. Sci. (Earth \& Planet. Sci.), 107, 1998, 65-90

Krishnan R, Zhang C, Sugi M. 2000. Dynamics of breaks in the Indian summer monsoon. J. Atmos. Sci. 57:1354-1372

Kumar KK, Rajagopalan B, Cane MA. 1999. On the Weakening Relationship Between the Indian Monsoon and ENSO. Science. 284 DOI: 10.1126/science.284.5423.2156

Li C, Yanai M. 1996. The onset and interannual variability of the Asian summer monsoon in relation to land-sea thermal contrast. J. Clim. 9:358-375 
Li W, Fu R. 2006. Influence of cold air intrusions on the wet season onset over Amazonia. $J$. Clim. 19:257-275

Meehl GA. 1987 The annual cycle and interannual variability in the tropical Pacific and Indian Ocean regions. Mon. Wea. Rev. 115: 27-50

Mitra AK, Bohra AK, Rajeevan M, Krishnamurti TN. 2009. Daily Indian precipitation analyses

" formed from a merged of rain-gauge with TRMM TMPA satellite derived rainfall estimates. J. Met. Soc. Japan. 87A:265-279

Pai DS, Rajeevan M. 2009. Summer monsoon onset over Kerala: New definition and prediction. J. Earth Syst. Sci. 118: 123-135

Pithan F, Mauritsen T. 2014. Arctic amplification dominated by temperature feedbacks in contemporary climate models. Nat. Geoscience. VOL 7, March 2014 DOI: 10.1038/NGEO2071

Rajeevan M, McPhaden J. 2004. Tropical Pacific upper ocean heat content variations and Indian summer monsoon rainfall. Geophys. Res. Lett. 31: L18203. doi:10.1029/2004GL020631

Rajeevan M, Gadgil S, Bhate J. 2010. Active abd break spells of the Indian summer monsoon. $J$. Earth. Syst. Sci. 119:229-247

Ramaswamy C. 1962. Breaks in the Indian summer monsoon as a phenomenon of interaction between easterly and the subtropical westerly jet streams. Tellus. 14:337-349

Ramesh KV, Krishnan R. 2005. Coupling of mixed layer processes and thermocline variations in the Arabian Sea. J. Geophys. Res. 110: C05005. doi:10.1029/2004JC002515 
Rao KG, Goswami BN. 1998. Interannual variations of sea surface temperature over the Arabian Sea and the Indian monsoon: A new perspective. Mon. Wea. Rev. 116: 558-568

Ratnam JV, Behera SK, Masumoto Y, Takahashi K, Yamagata T. 2010. Pacific Ocean origin for the 2009 Indian summer monsoon failure. Geophys. Res. Lett. 37: L07807 doi:10.1029/2010GL042798

Reynolds RW, Smith TM, Liu C, Chelton DB, Casey KS, Schlax MG. 2007. Daily HighResolution-Blended Analyses for Sea Surface Temperature. J. Clim. 20: 5473-5496.

Saha S, co-authors. 2014. The NCEP Climate Forecast System Version 2. J. Clim. 27:21852208. doi:http://dx.doi.org/10.1175/JCLI-D-12-00823.1

Sahai AK, Abhilash S, Chattopadhyay R, Borah N, Joseph S, Sharmila S, Rajeevan M. 2015. High-resolution operational monsoon forecasts: an objective assessment. Clim. Dyn. 44: 3129-3140. June 2015. DOI:10.1007/s00382-014-2210-9.

Sahai AK, Sharmila S, Abhilash S, Chattopadhyay R, Borah N, Krishna RPM, Joseph S, Roxy M, De S, Pattnaik S, Pillai PA. 2013. Simulation and extended range prediction of monsoon intraseasonal oscillations in NCEP CFS/GFS version 2 framework, Curr. Sci. 104. No.10. 25 May 2013

Sahai AK, Chattopadhyay R, Joseph S, Mandal R, Dey A, Abhilash S, Krishna RPM, Borah N. 2015. Real-time Performance of a multi-model ensemble based extended range forecast system in predicting the 2014 monsoon season based on NCEP-CFSv2. Curr. Sci. in press. Screen JA, Simmonds I. 2010. The central role of diminishing sea ice in recent Arctic temperature amplification. Nature. 464. doi:10.1038/nature09051 
Sikka DR. 2011. Synoptic and mesoscale weather disturbances over South Asia during the southwest summer monsoon season. The Global Monsoon System: Research and Forecast. Chang CP et al. (Eds). 2nd Edition. World Scientific: New Jersey, pp 183-204

Slingo J, Annamalai H. 2000.

Wu X, Moorthi KS, Okomoto K, Pan HL. 2005. Sea ice impacts on GFS forecasts at high latitudes. Preprints Eighth Conf. on Polar Meteorology and Oceanography, San Diego CA Amer Meteor Soc 7.4 [http://ams.confex.com/ams/pdfpapers/84292.pdf]

Xavier PK, Marzin C, Goswami BN. 2007. An objective definition of the Indian summer monsoon season and a new perspective on ENSO-monsoon relationship. Quart. J. Meteorol. Soc. 133: 749-764

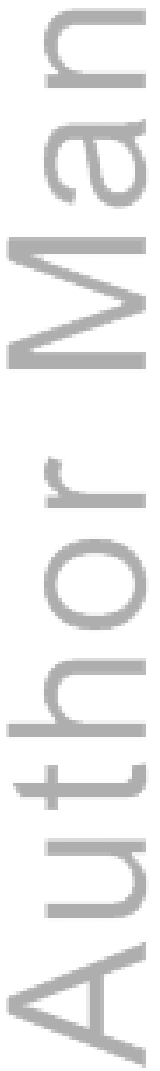


Table 1: Observed June rainfall in $\mathrm{mm}$ and its \% departure from long term mean. Years with excess (deficit) June rainfall are marked in bold (bold + italics) font. The onset date, the date on which the ISM covered the whole country and the total number of days taken for the same are also given in the table.

\begin{tabular}{|c|c|c|c|c|c|}
\hline Year & $\begin{array}{c}\text { June } \\
\text { Rainfall } \\
(\mathrm{mm})\end{array}$ & $\begin{array}{c}\text { Departure } \\
\text { from Mean in } \\
\%\end{array}$ & MOK Date & $\begin{array}{l}\text { Date of } \\
\text { covering the } \\
\text { entire country }\end{array}$ & $\begin{array}{l}\text { Total Days } \\
\text { taken to cover } \\
\text { the country }\end{array}$ \\
\hline 200 & 219.0 & 35.6 & 23 May & 24 June & 32 \\
\hline 2002 & 180.1 & 9.4 & 29 May & 15 August & 66 \\
\hline 2003 & 179.9 & 9.8 & 08 June & 05 July & 28 \\
\hline 2004 & 158.7 & -0.8 & 18 May & 18 July & 62 \\
\hline 200 & 143.2 & -9.5 & 05 June & 30 June & 26 \\
\hline 2006 & 141.8 & -12.7 & 26 May & 24 July & 60 \\
\hline 2007 & 192.5 & 18.5 & 28 May & 04 July & 38 \\
\hline 2008 & 202.0 & 24.3 & 31 May & 10 July & 41 \\
\hline 2009 & 85.7 & -47.2 & 23 May & 03 July & 42 \\
\hline 2010 & 138.1 & -15.6 & 31 May & 06 July & 37 \\
\hline 2011 & 183.5 & 12.2 & 29 May & 09 July & 42 \\
\hline 2012 & 117.8 & -28.0 & 05 June & 11 July & 37 \\
\hline
\end{tabular}

This article is protected by copyright. All rights reserved. 


\begin{tabular}{|c|c|c|c|c|c|}
\hline 2013 & 219.8 & 34.4 & 01 June & 16 June & 16 \\
\hline 2014 & 92.4 & -43.5 & 06 June & 17 July & 42 \\
\hline
\end{tabular}

\section{Figure Captions}

Figure 1: (a) Rainfall anomaly $\left(\mathrm{mm} \mathrm{day}^{-1}\right)$ and (b) $850 \mathrm{hPa}$ anomalous wind ( $\mathrm{m} \mathrm{s}^{-1}$; streamlines) and the KE ( $\mathrm{m}^{2} \mathrm{~s}^{-2}$; shaded) of its rotational component, during June 2013. (c) and (d) are same as (a) and (b), but for 2014.

Figure 2: Time - height evolution of anomalous omega (pressure vertical velocity in $\mathrm{hPa} \mathrm{s}{ }^{-1}$ multiplied by -1.0 ; shaded) over Central India $\left(70^{\circ}-85^{\circ} \mathrm{E} ; 15^{\circ}-25^{\circ} \mathrm{N}\right)$ during (a) 2013 and (b) 2014. (c) and (d) show the monsoon Hadley circulation anomalies during June 2013 and 2014 respectively. To construct the meridional circulation anomalies, the meridional and vertical velocities are averaged over the longitudes $70^{\circ}-90^{\circ} \mathrm{E}$. The shading represents omega $\left(\mathrm{hPa} \mathrm{s}^{-1}\right)$ anomalies taken with a negative sign.

Figure 3: (a) Moist Static Energy (MSE; kJ kg-1) anomalies and (b) vertically integrated (surface to $500 \mathrm{hPa}$ ) moisture $\left(\mathrm{mm} \mathrm{day}^{-1}\right)$ anomalies, during June 2013. (c) and (d) are same as (a) and (b), but for 2014 .

Figure 4: Sea surface temperature (unit: ${ }^{\circ} \mathrm{C}$ ) anomalies during June (a) 2013 and (b) 2014. Velocity potential (x $10^{-5} \mathrm{~m}^{2} \mathrm{~s}^{-1}$; shaded) and divergent wind anomalies $\left(\mathrm{ms}^{-1}\right.$; vector) at $200 \mathrm{hPa}$ during June (c) 2013 and (d) 2014. Longitude-height cross-sections depicting the east-west (Walker) circulation anomalies over Indo-Pacific region during June (e) 2013 and (f) 2014. For constructing the east-west circulation anomalies, the zonal and vertical 
velocities are averaged over the latitudes $\left(5^{\circ} \mathrm{S}-5^{\circ} \mathrm{N}\right)$. The shading represents omega $(\mathrm{hPa} \mathrm{s}$

$\left.{ }^{1}\right)$ anomalies taken with a negative sign.

Figure 5: Time evolution of north-south TT gradient (K) during 2013 and 2014.

Figure 6: $200 \mathrm{hPa}$ zonal wind ( $\mathrm{m} \mathrm{s}^{-1}$; vector) during June 2013 and 2014. Magnitude of wind is shaded in the figure. Figures (a) and (d) corresponds to the period 01-10 June, whereas (b)

$=$ and (e) represents 11-20 June; and (c) and (f) stands for 21-30 June.

Figure 7: Pentad-wise percentage departure of rainfall over monsoon zone (defined by Rajeevan et al.2010) for observation as well as pentad 1 to pentad 4 (P1-P4) lead times.

Figure 8: (a) to (d) same as Figure 1(a), (e) to (h) same as Figure 1(c), (i) to (1) same as Figure 1(b), and (m) to (p) same as Figure 1(d); but for P1 to P4 leads of MME.

Figure 9: (a) to (d) same as Figure 2(a), (e) to (h) same as Figure 2(b), (i) to (l) same as Figure 2(c), and (m) to (p) same as Figure 2(d); but for P1 to P4 leads of MME.

Figure 10: (a) to (d) same as Figure 4(c), (e) to (h) same as Figure 4(d), (i) to (l) same as top panel of Figure 4e and (m) to (p) same as bottom panel of Figure 4f; but for P1 to P4 leads of MME.

Figure 11: Same as Figure 5, but for P1 to P4 leads of MME.

Figure 12: Same as Figure 6, but for P1 to P4 leads of MME. Here, (a)-(f), (g)-(l), (m)-(r) and (S)-(x) are for P1, P2, P3 and P4 lead times respectively.

\section{Supplementary Figures}

Suppl. Figure S1: Same as Figure 4 (a) and (b), but for 2001 and 2009. 
Suppl. Figure S2: TT anomaly (K) during (a) June 2013, (b) June 2014, (c) January to May 2013 and (d) January to May 2014.

Suppl. Figure S3: Same as Figure 5, but for 2001 and 2009.

Suppl. Figure S4: (a)-(d) is same as Suppl. Figure S1(a), whereas (e)-(f) is same as Suppl. Figure
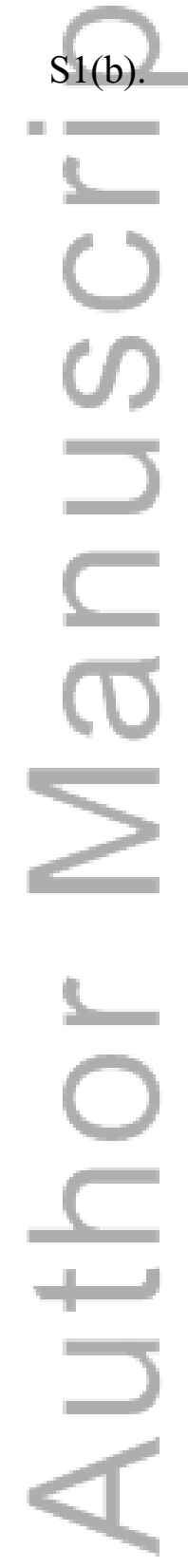

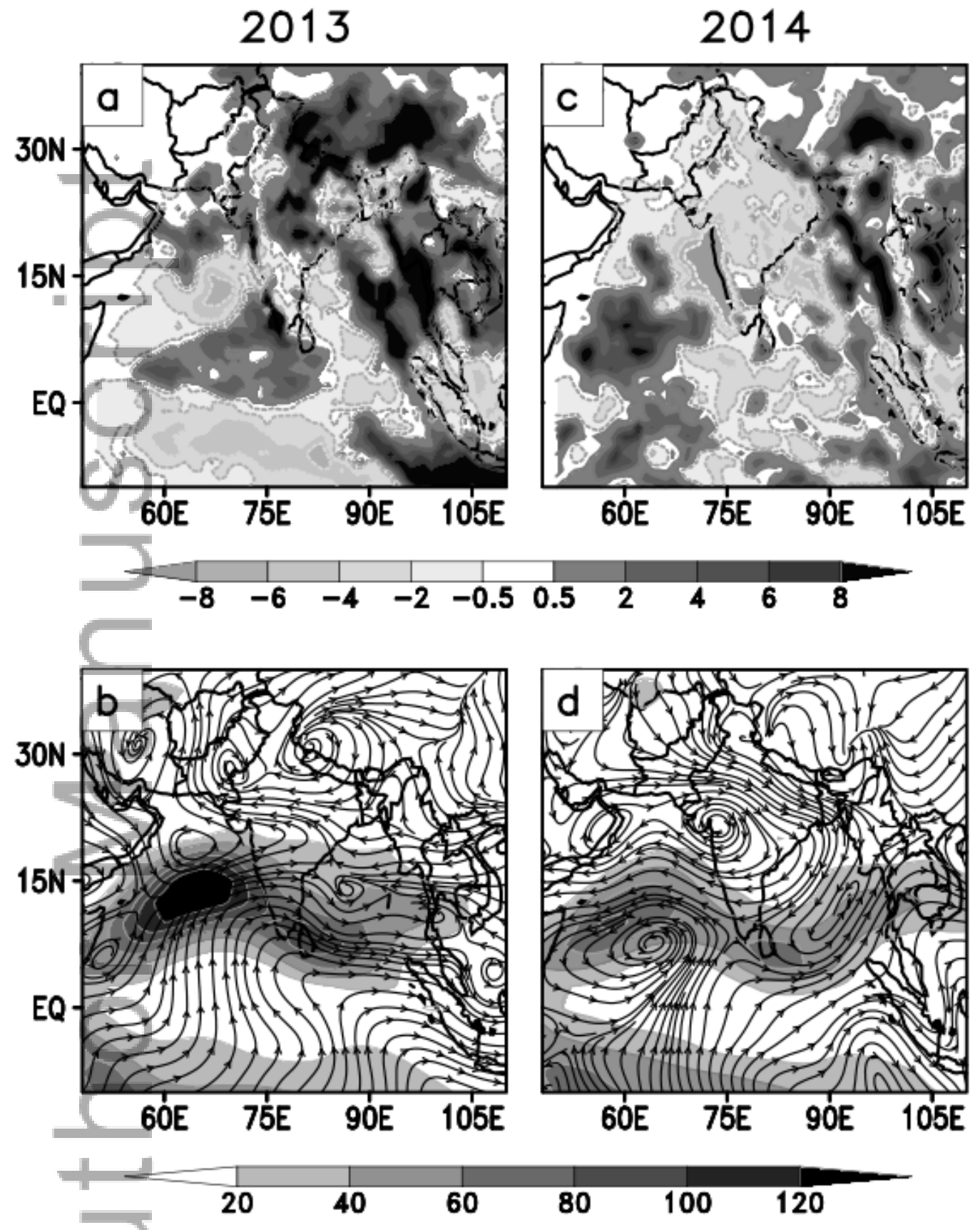

Figure 1: (a) Rainfall anomaly $\left(\mathrm{mm} \mathrm{day}^{-1}\right)$ and (b) $850 \mathrm{hPa}$ anomalous wind ( $\mathrm{m} \mathrm{s}^{-1}$; streamlines) and the KE ( $\mathrm{m}^{2} \mathrm{~s}^{-2}$; shaded) of its rotational component, during June 2013. (c) and (d) are same as (a) and (b), but for 2014. 


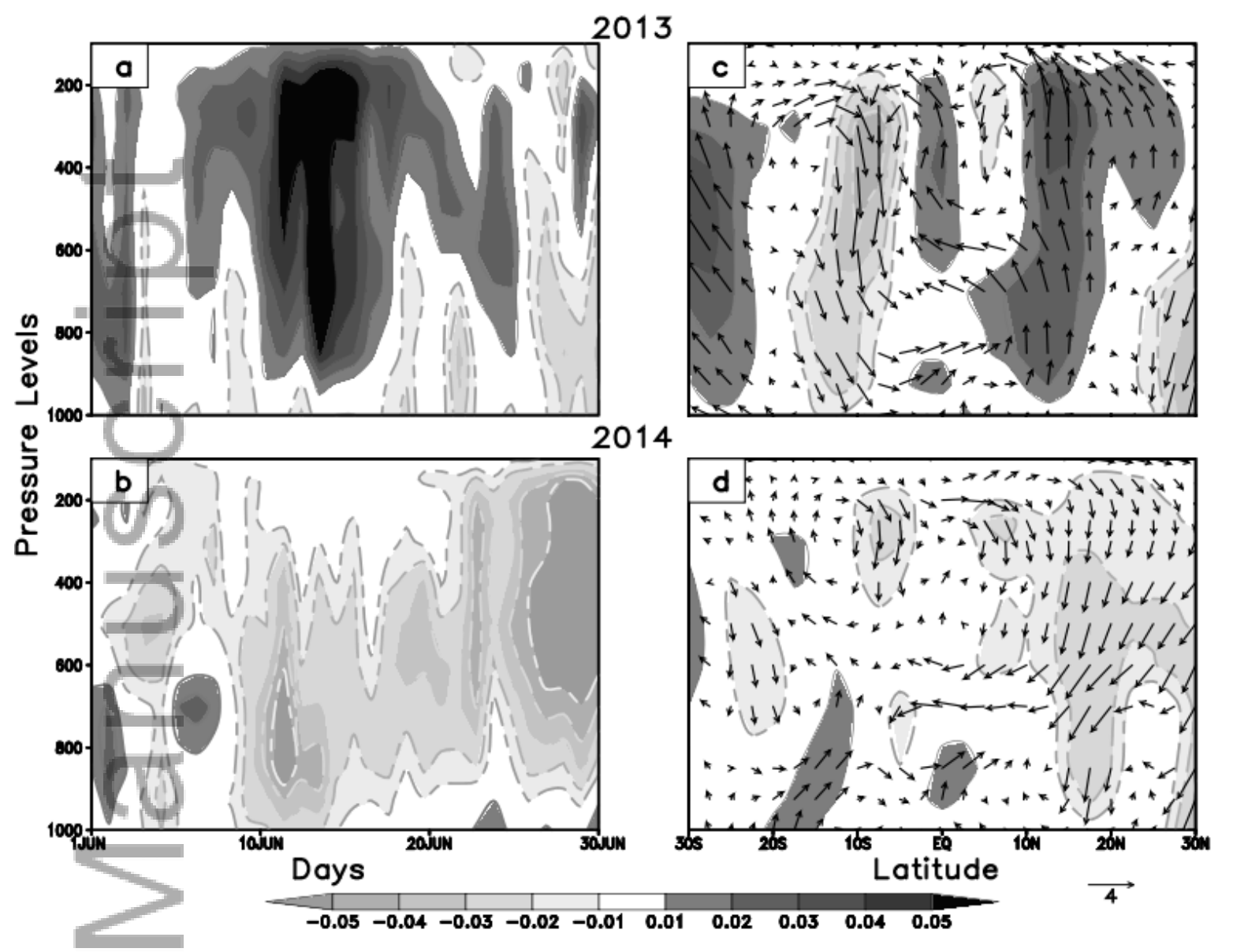

Figure 2: Time - height evolution of anomalous omega (pressure vertical velocity in hPa s${ }^{-1}$ multiplied by -1.0 ; shaded) over Central India $\left(70^{\circ}-85^{\circ} \mathrm{E} ; 15^{\circ}-25^{\circ} \mathrm{N}\right)$ during (a) 2013 and (b) 2014. (c) and (d) show the monsoon Hadley circulation anomalies during June 2013 and 2014 respectively. To construct the meridional circulation anomalies, the meridional and vertical velocities are averaged over the longitudes $70^{\circ}-90^{\circ} \mathrm{E}$. The shading represents omega $\left(\mathrm{hPa} \mathrm{s}^{-1}\right)$ anomalies taken with a negative sign.

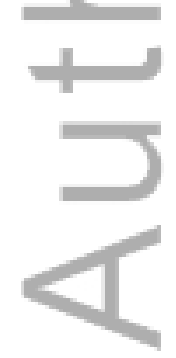




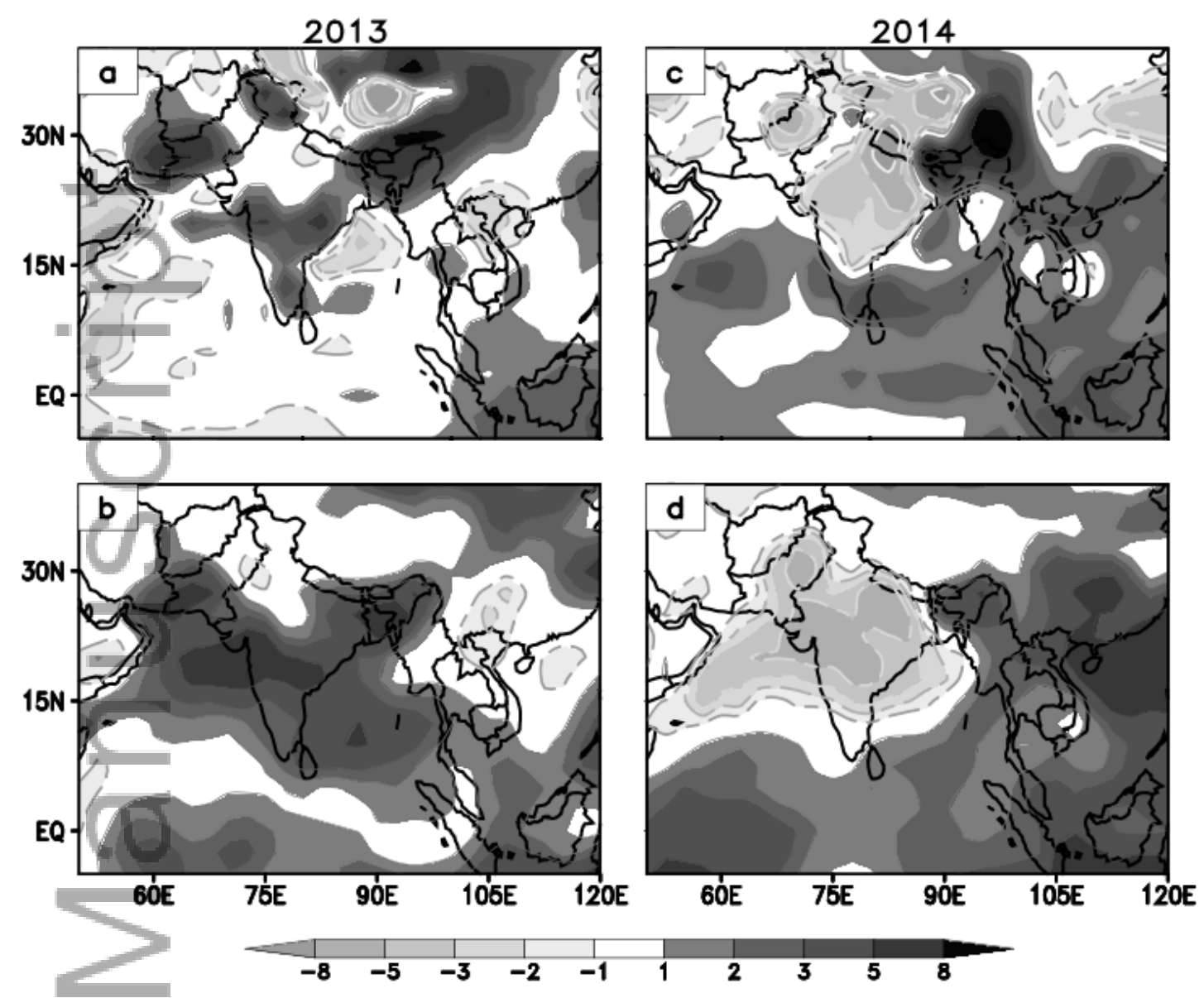

Figure 3: (a) Moist Static Energy (MSE; $\mathrm{kJ} \mathrm{kg}^{-1}$ ) anomalies and (b) vertically integrated (surface to $500 \mathrm{hPa}$ ) moisture (mm day ${ }^{-1}$ ) anomalies, during June 2013. (c) and (d) are same as (a) and (b), but for 2014.

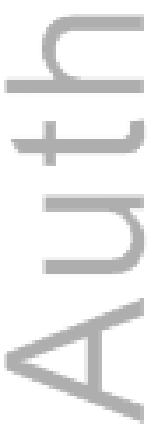



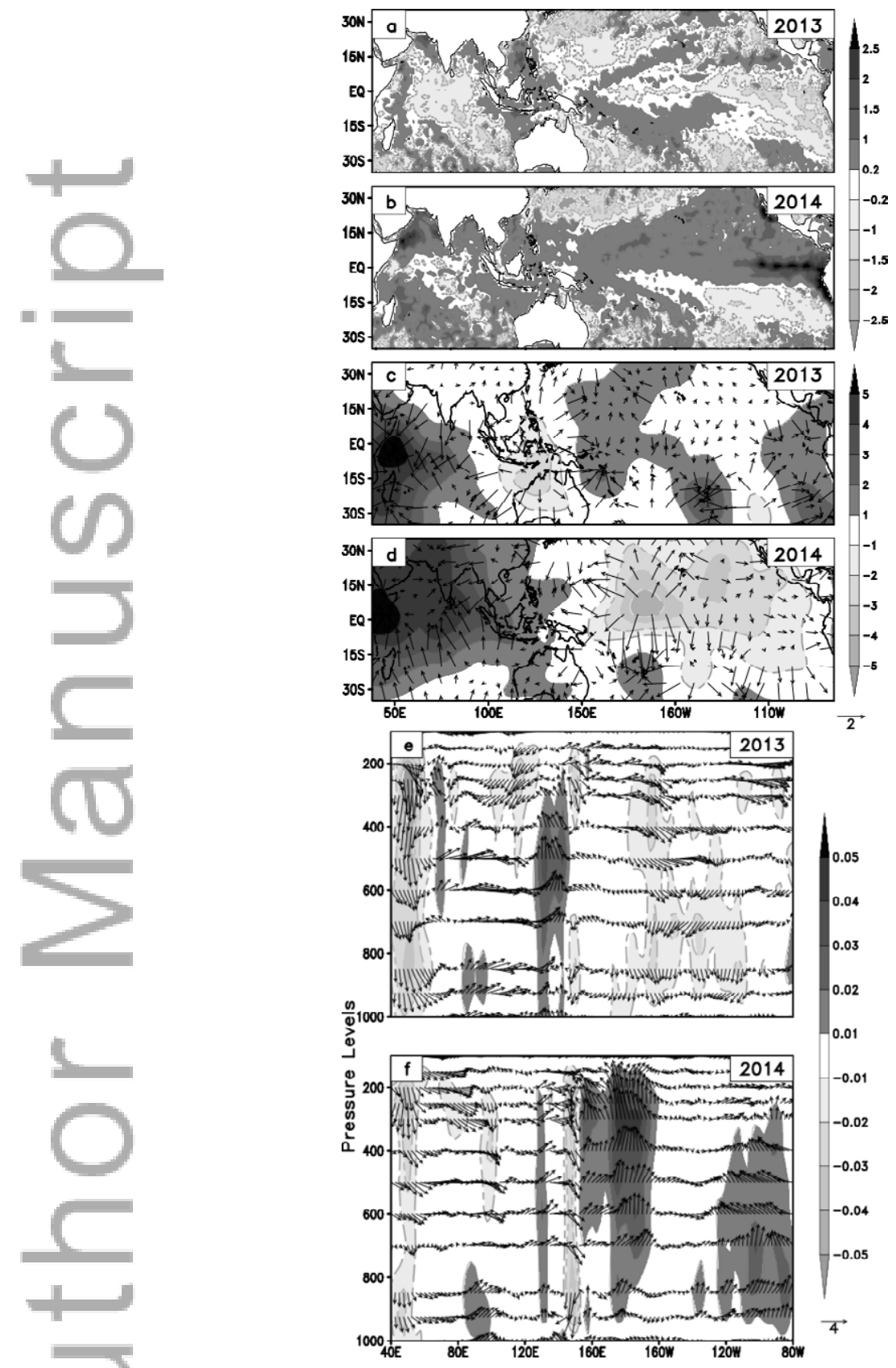

Figure 4: Sea surface temperature (unit: ${ }^{\circ} \mathrm{C}$ ) anomalies during June (a) 2013 and (b) 2014. Velocity potential $\left(\times 10^{-5} \mathrm{~m}^{2} \mathrm{~s}^{-1}\right.$; shaded $)$ and divergent wind anomalies $\left(\mathrm{ms}^{-1}\right.$; vector $)$ at $200 \mathrm{hPa}$ during June (c) 2013 and (d) 2014. Longitude-height cross-sections depicting the east-west 
(Walker) circulation anomalies over Indo-Pacific region during June (e) 2013 and (f) 2014. For constructing the east-west circulation anomalies, the zonal and vertical velocities are averaged over the latitudes $\left(5^{\circ} \mathrm{S}-5^{\circ} \mathrm{N}\right)$. The shading represents omega $\left(\mathrm{hPa} \mathrm{s}^{-1}\right)$ anomalies taken with a negative sign.

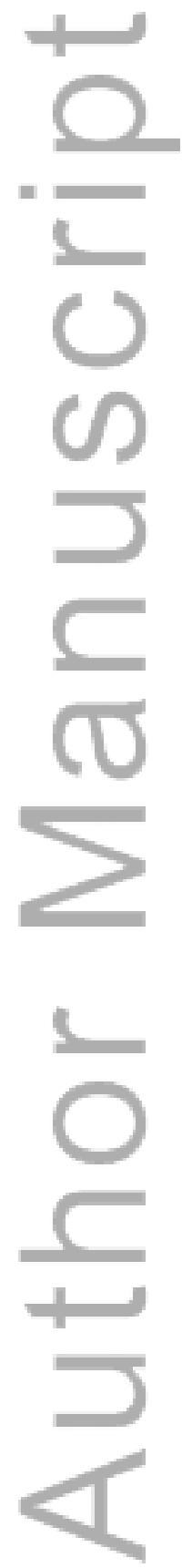




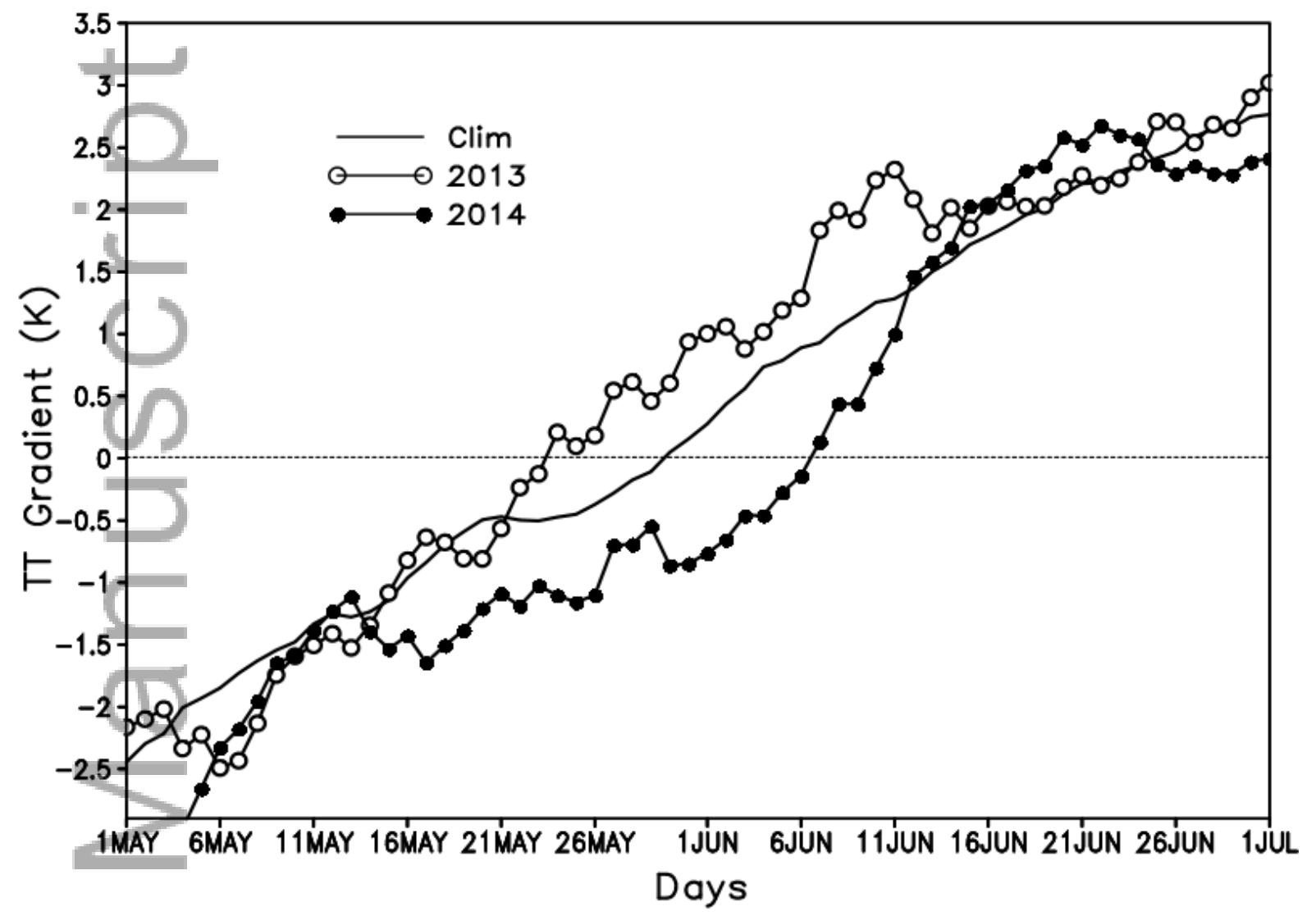

Figure 5: Time evolution of north-south TT gradient (K) during 2013 and 2014.

This article is protected by copyright. All rights reserved. 

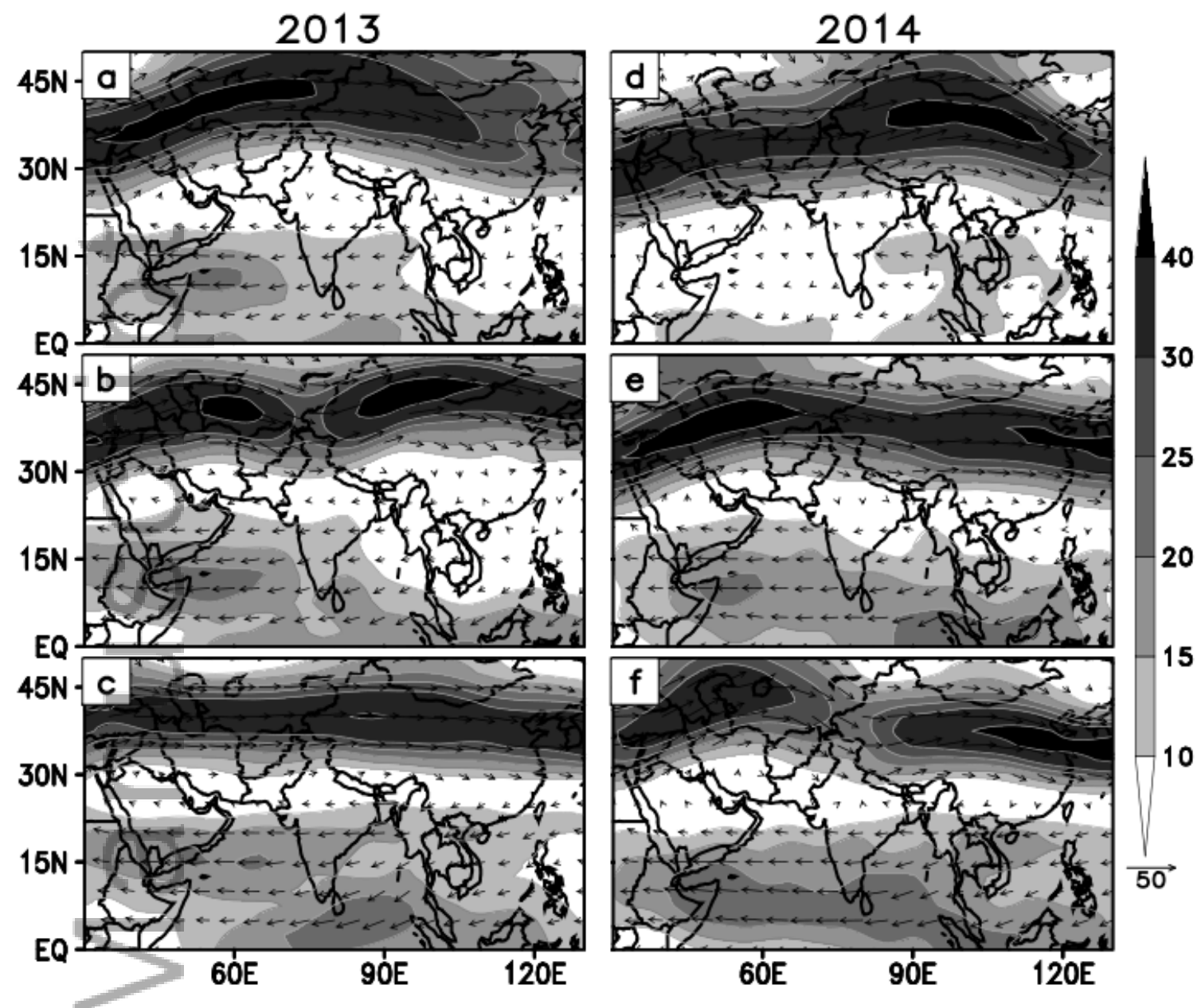

Figure 6: $200 \mathrm{hPa}$ zonal wind ( $\mathrm{m} \mathrm{s}^{-1}$; vector) during June 2013 and 2014. Magnitude of wind is shaded in the figure. Figures (a) and (d) corresponds to the period 01-10 June, whereas (b) and (e) represents 11-20 June; and (c) and (f) stands for 21-30 June.

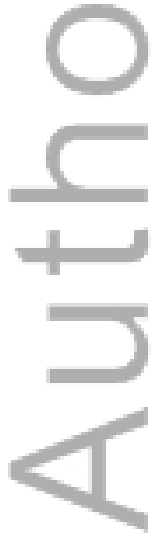



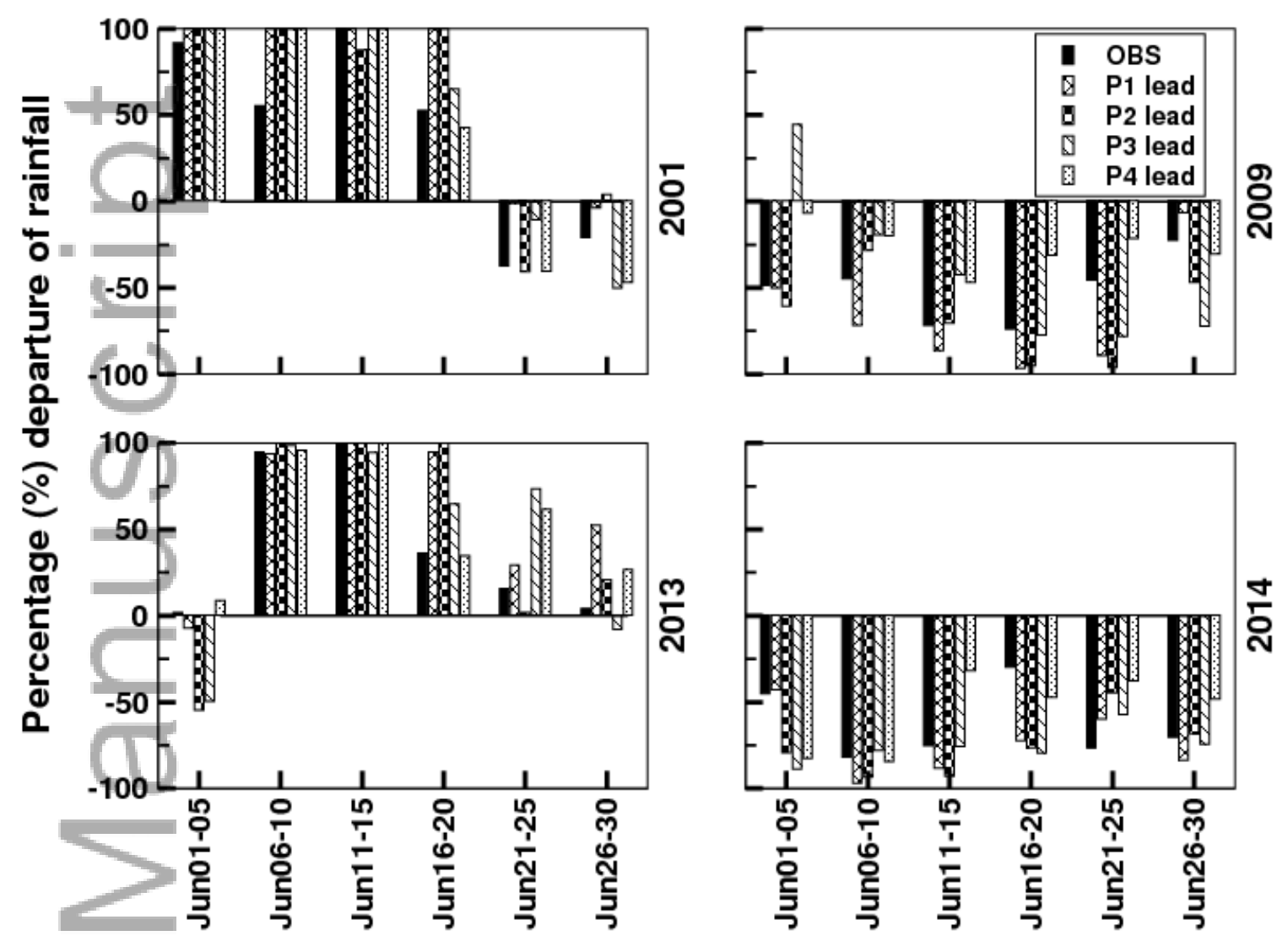

Figure 7: Pentad-wise percentage departure of rainfall over monsoon zone (defined by Rajeevan et al. 2010) for observation as well as pentad 1 to pentad 4 (P1-P4) lead times. 

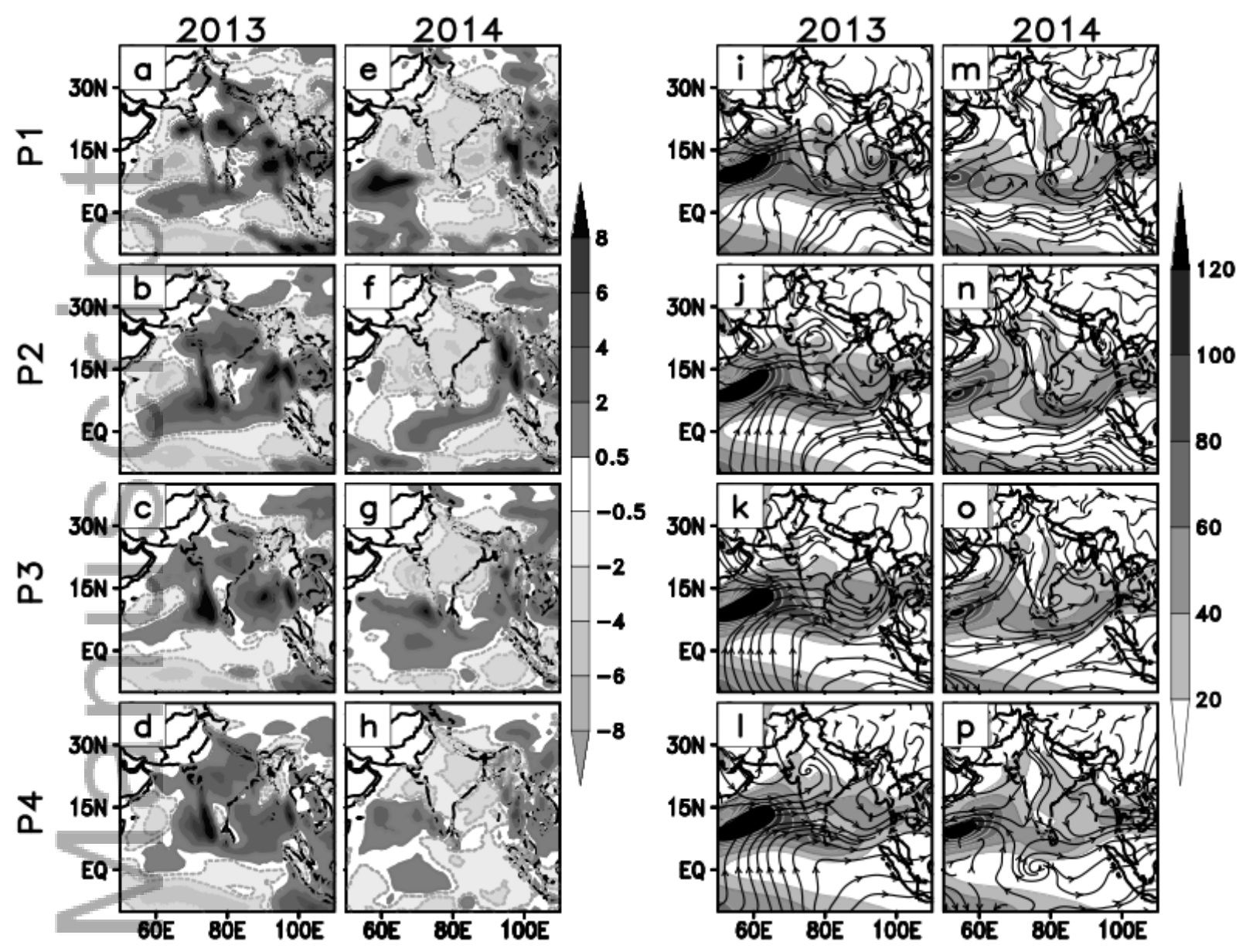

Figure 8: (a) to (d) same as Figure 1(a), (e) to (h) same as Figure 1(c), (i) to (l) same as Figure $1(\mathrm{~b})$, and $(\mathrm{m})$ to $(\mathrm{p})$ same as Figure $1(\mathrm{~d})$; but for P1 to P4 leads of MME.

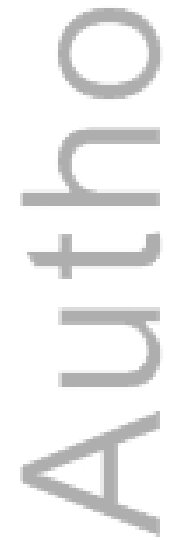



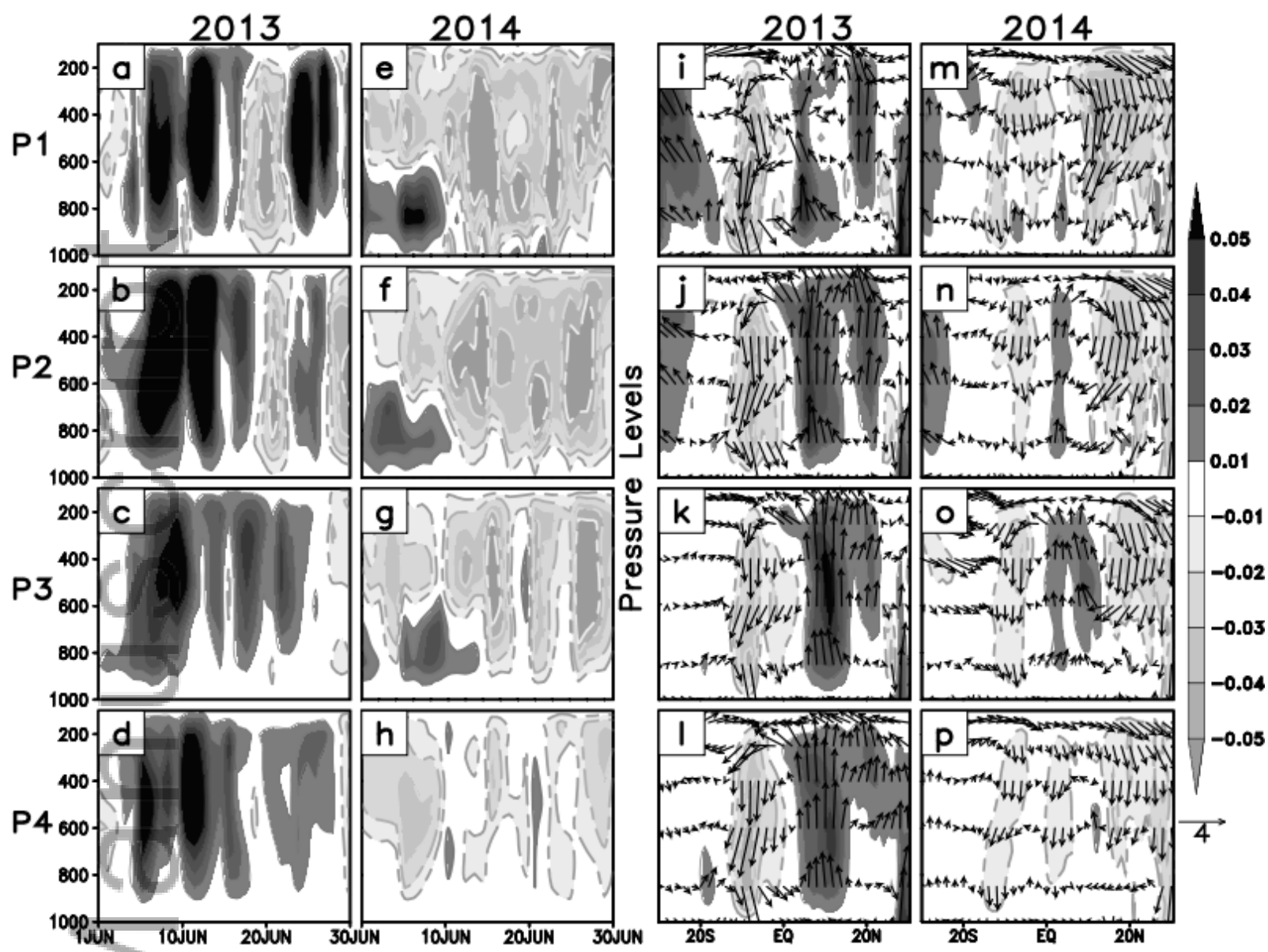

Figure 9: (a) to (d) same as Figure 2(a), (e) to (h) same as Figure 2(b), (i) to (l) same as Figure 2(c), and (m) to (p) same as Figure 2(d); but for P1 to P4 leads of MME.

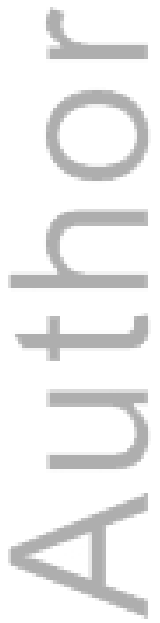




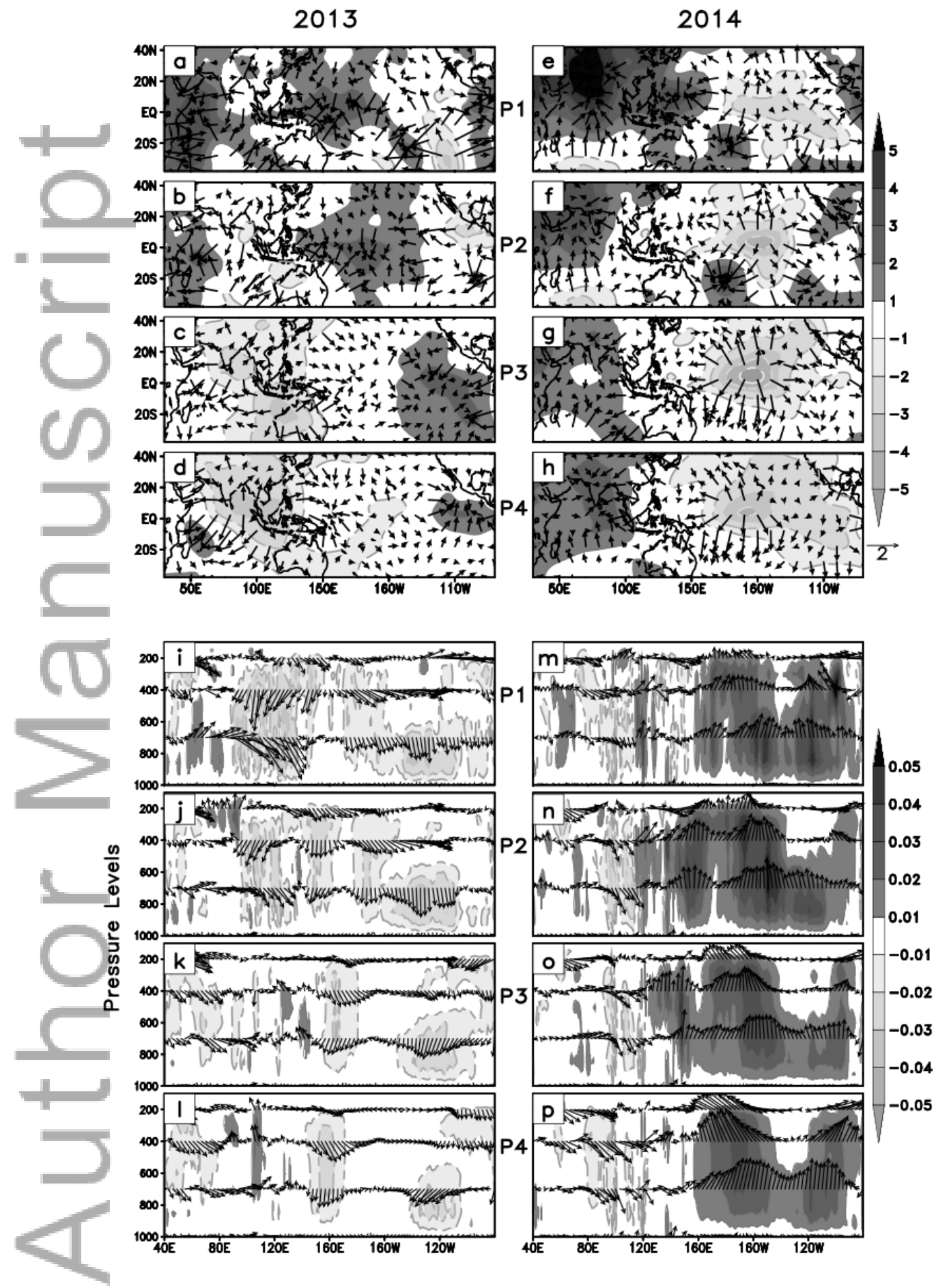

This article is protected by copyright. All rights reserved. 
Figure 10: (a) to (d) same as Figure 4(c), (e) to (h) same as Figure 4(d), (i) to (1) same as top panel of Figure 4e and (m) to (p) same as bottom panel of Figure 4f; but for P1 to P4 leads of MME.

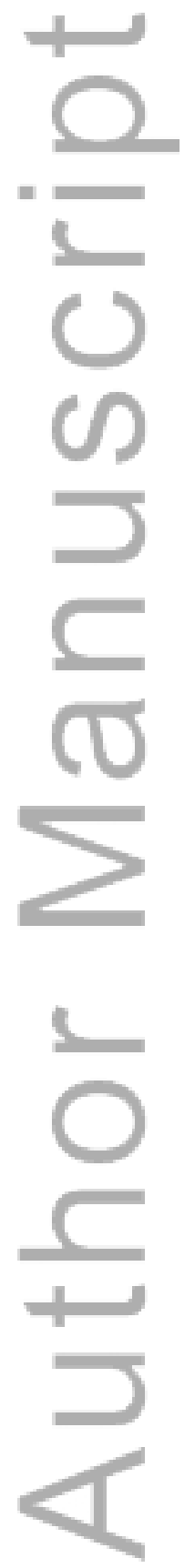




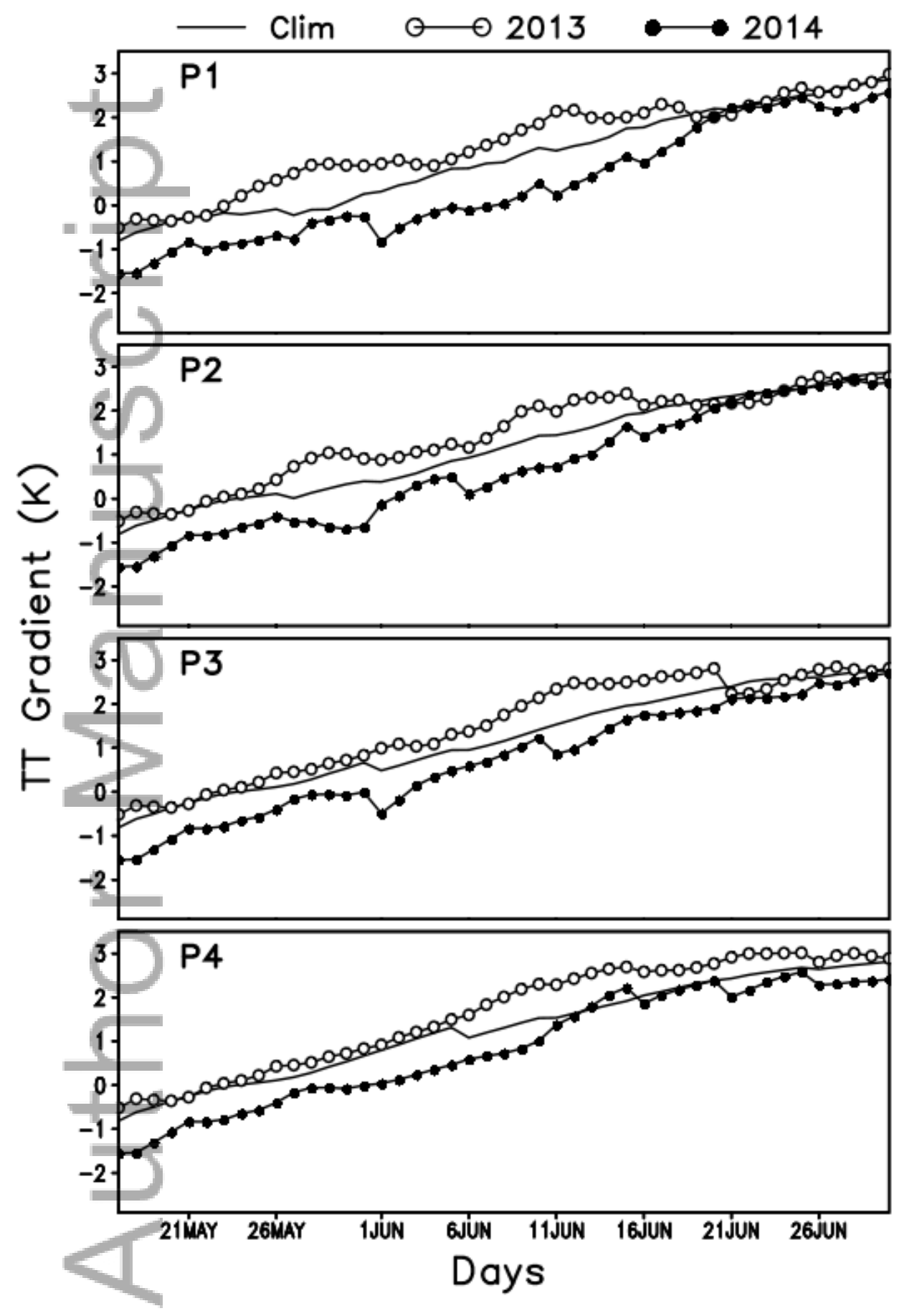


Figure11: Same as Figure 5, but for P1 to P4 leads of MME.

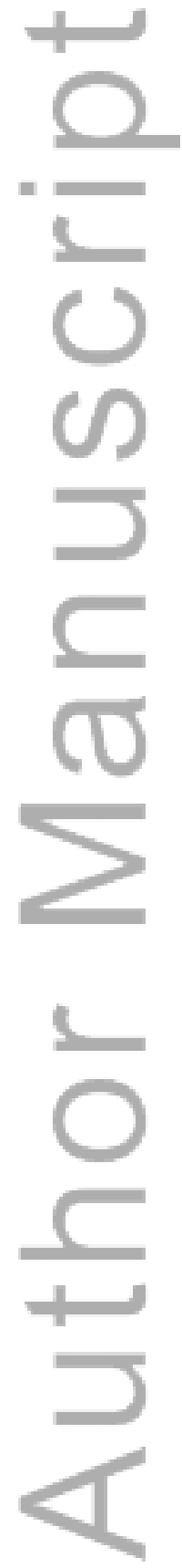



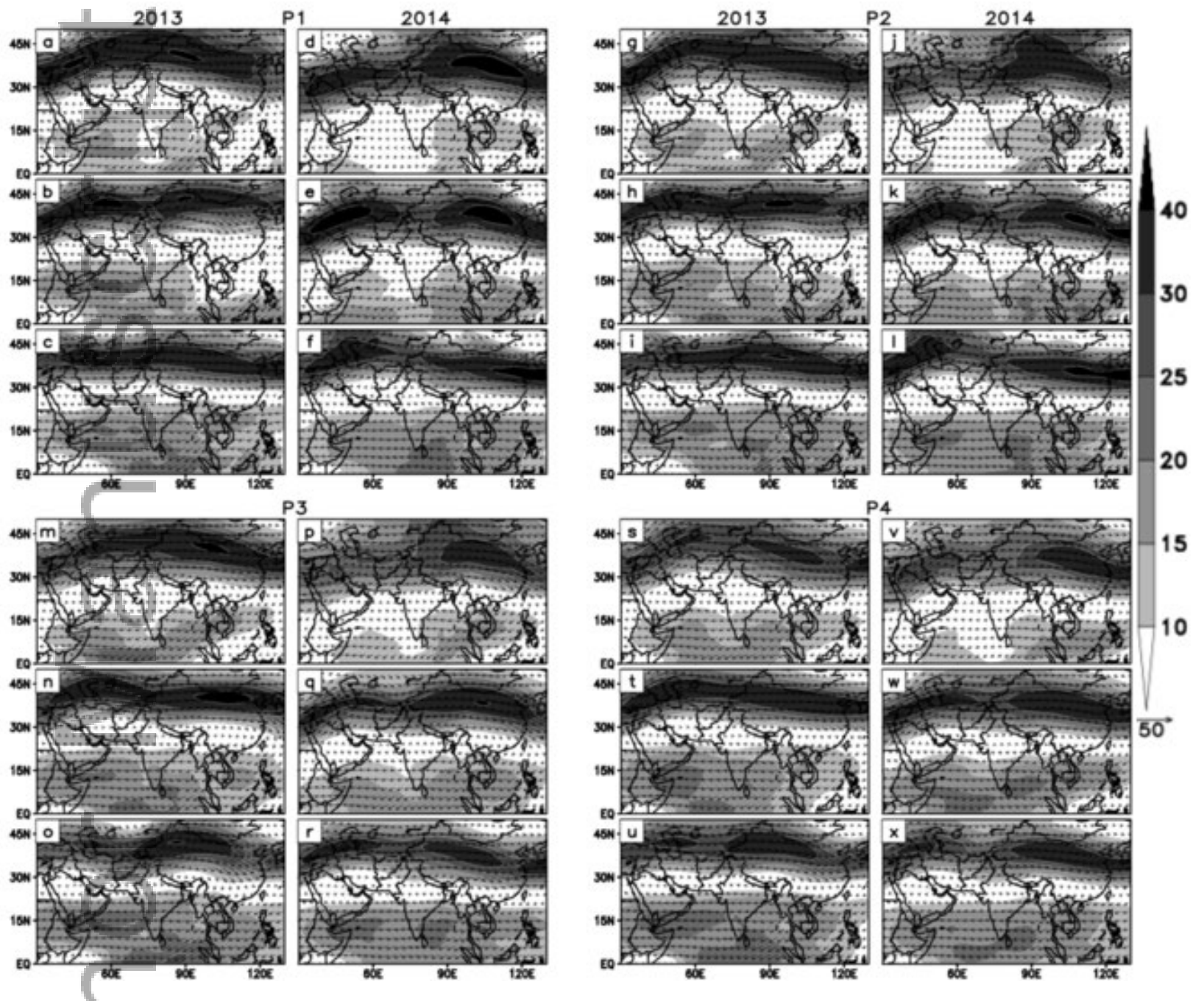

Figure 12: Same as Figure 6, but for P1 to P4 leads of MME. Here, (a)-(f), (g)-(1), (m)-(r) and (s)-(x) are for P1, P2, P3 and P4 lead times respectively.

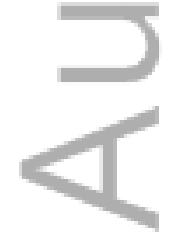




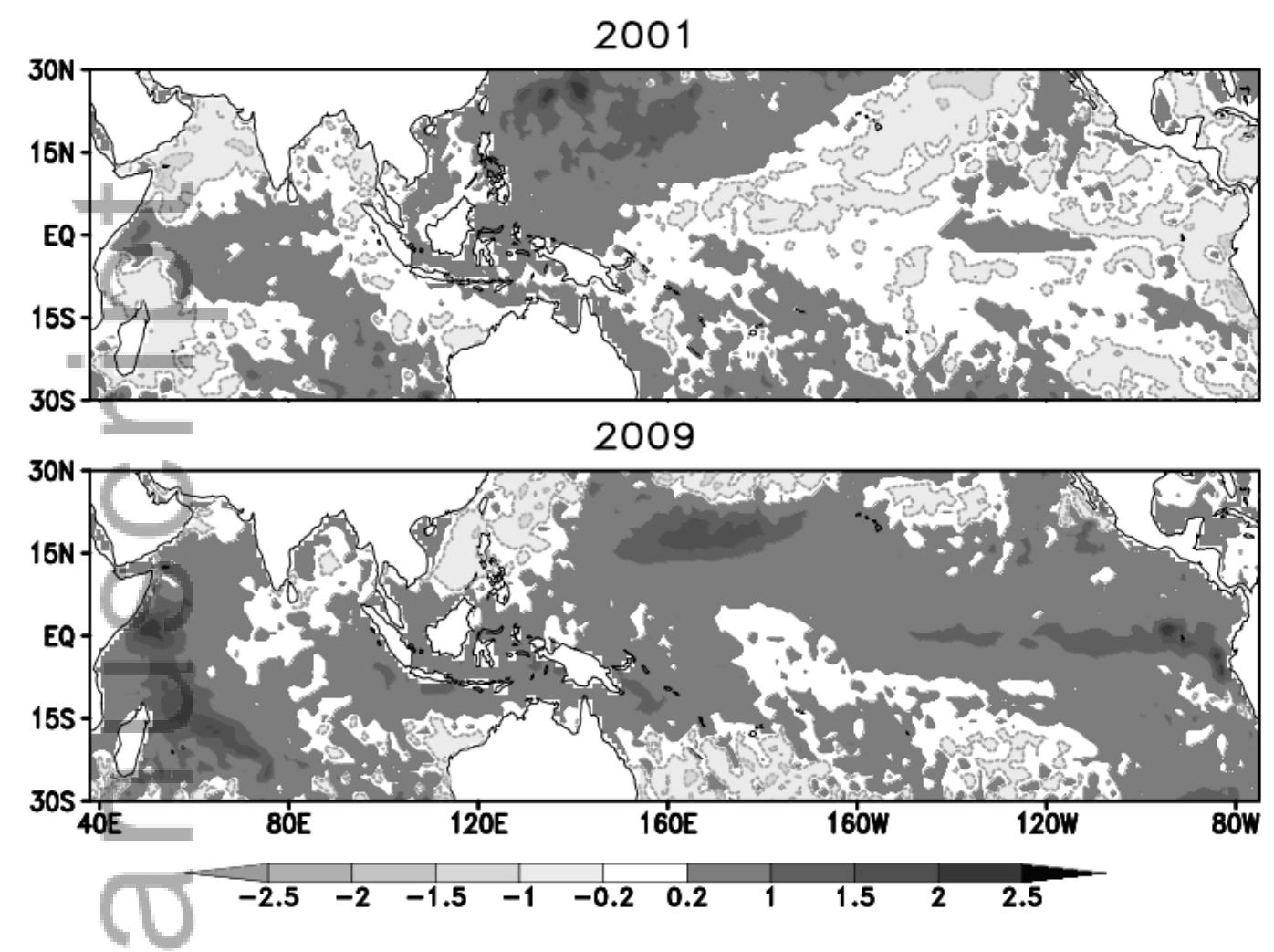

Suppl. Figure S1: Same as Figure 4 (a) and (b), but for 2001 and 2009.

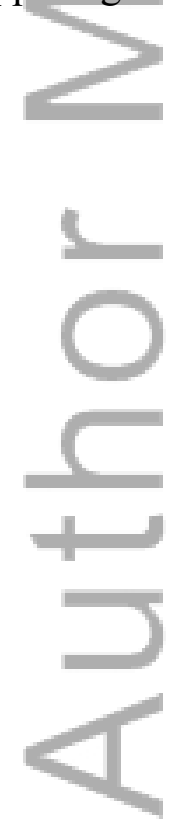



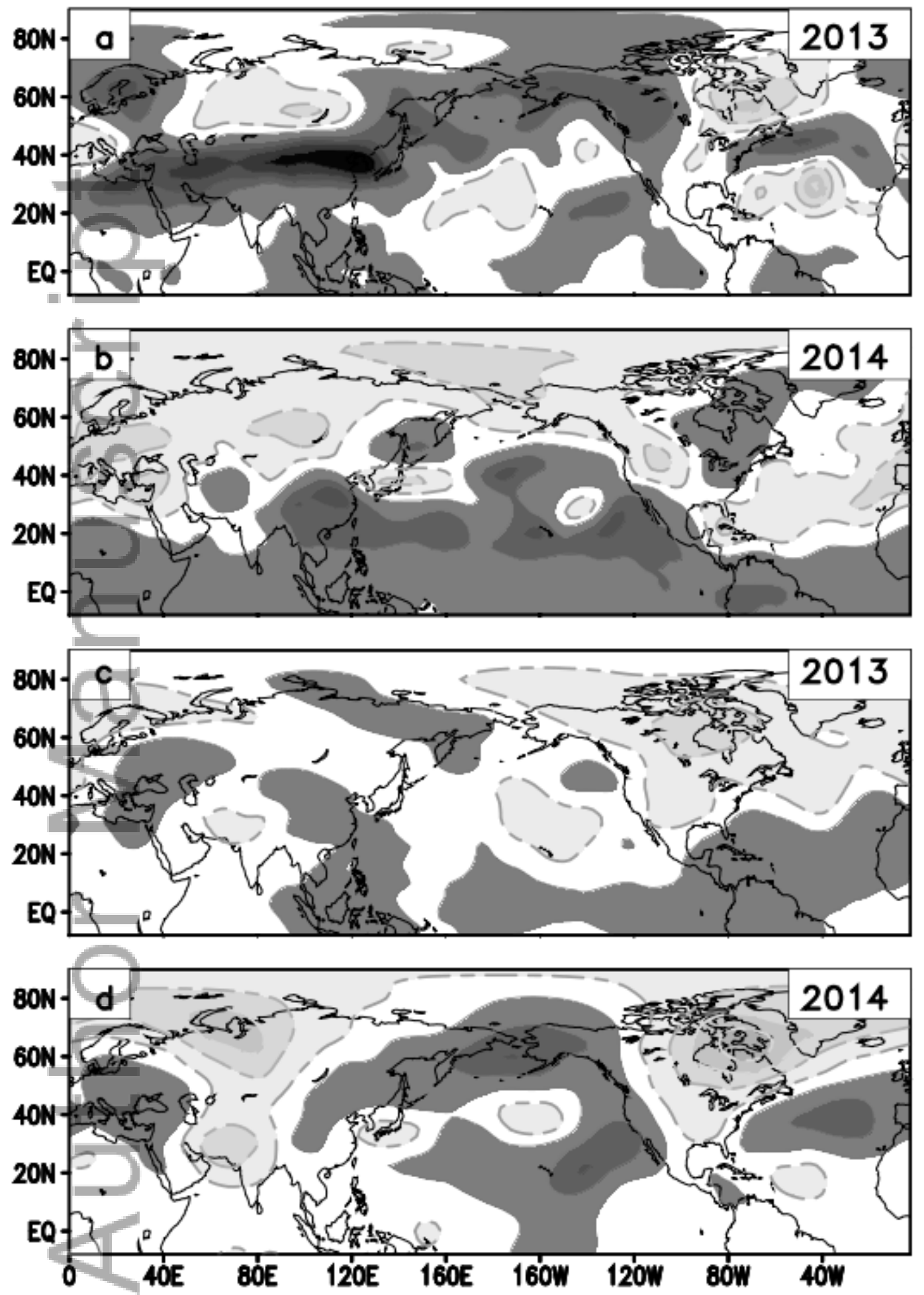
Suppl. Figure S2: TT anomaly (K) during (a) June 2013, (b) June 2014, (c) January to May 2013 and (d) January to May 2014.

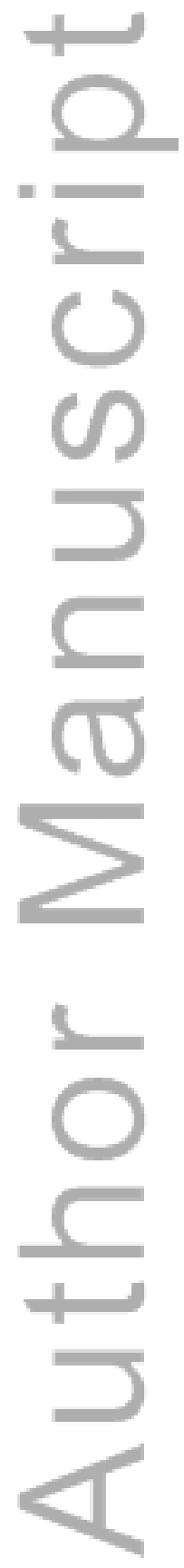




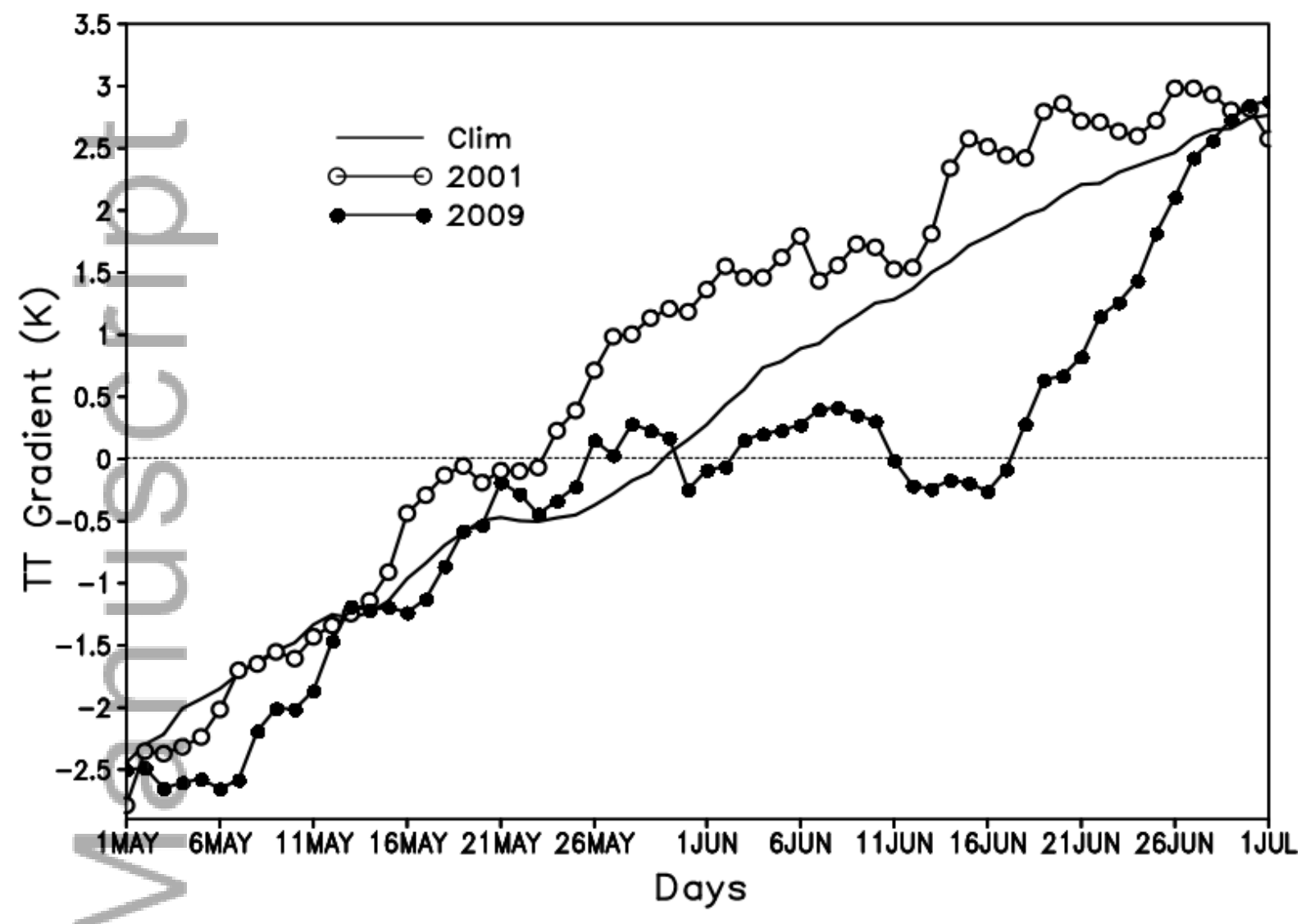

Suppl. Figure S3: Same as Figure 5, but for 2001 and 2009.

This article is protected by copyright. All rights reserved. 
2013
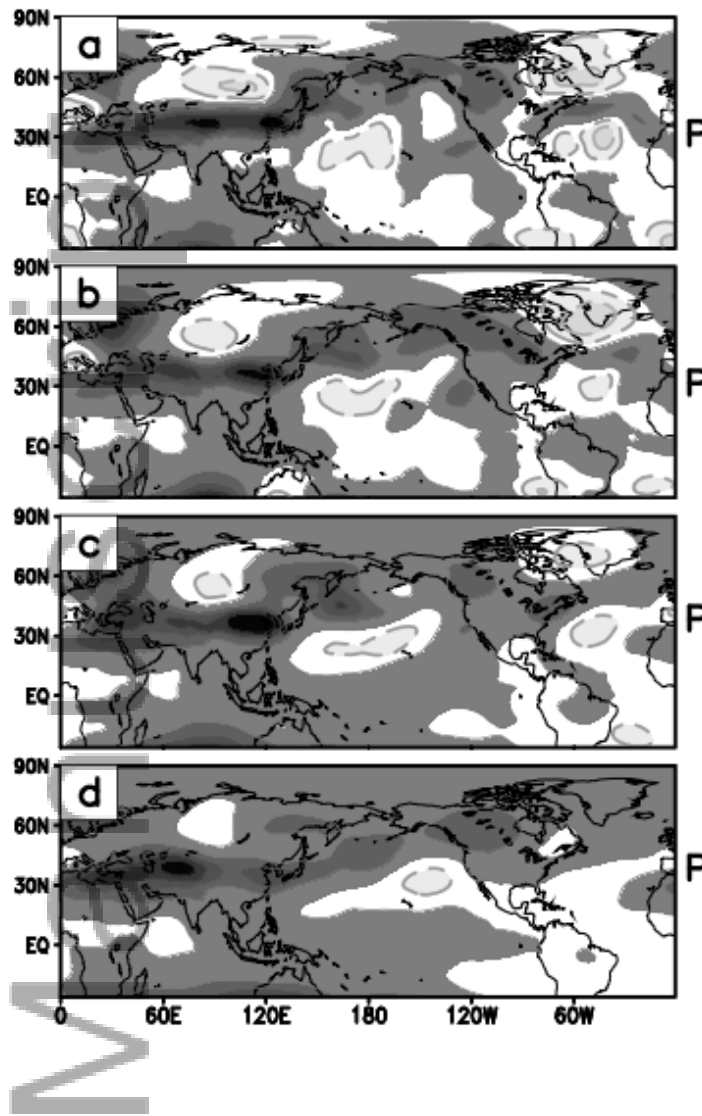

2014
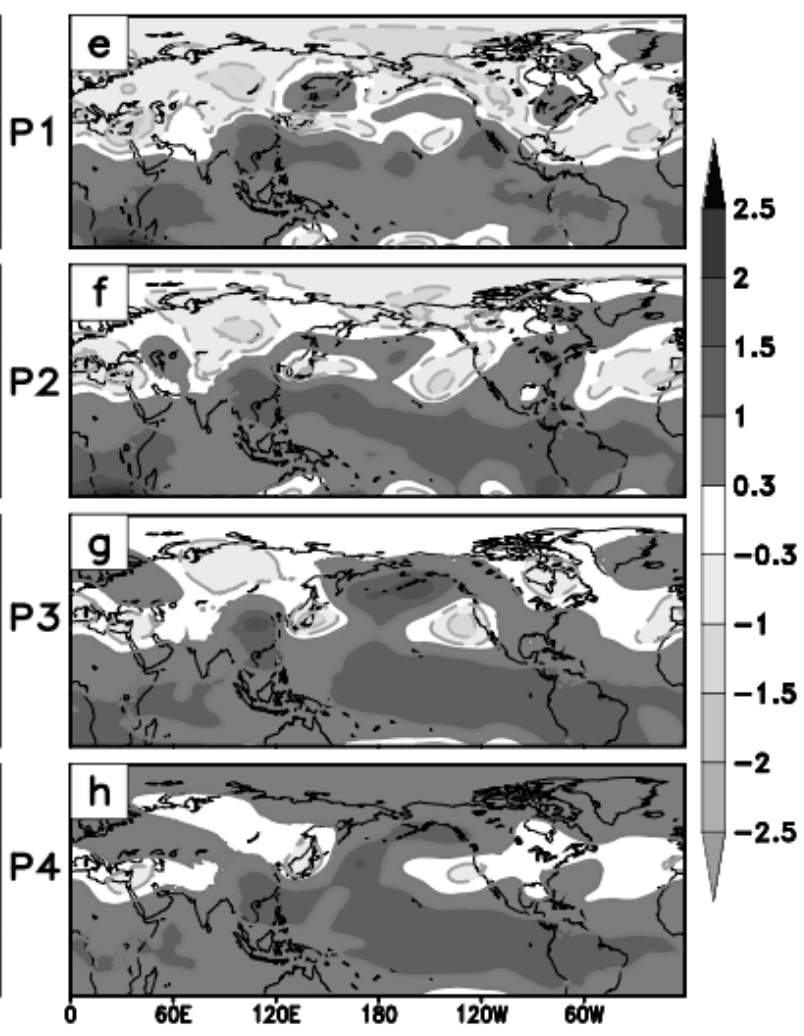

Suppl. Figure S4: (a)-(d) is same as Suppl. Figure S2(a), whereas (e)-(f) is same as Suppl. Figure $\mathrm{S} 2 \mathrm{~b})$.

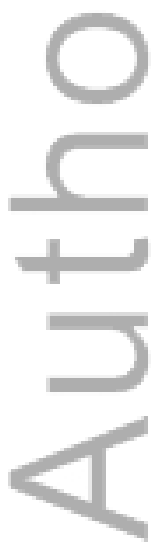




\section{University Library}

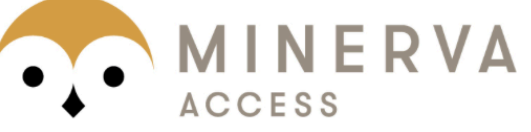

A gateway to Melbourne's research publications

Minerva Access is the Institutional Repository of The University of Melbourne

\section{Author/s:}

Joseph, S;Sahai, AK;Chattopadhyay, R;Sharmila, S;Abhilash, S;Rajeevan, M;Mandal, R;Dey, A;Borah, N;Phani, R

Title:

Extremes in June rainfall during the Indian summer monsoons of 2013 and 2014:

observational analysis and extended-range prediction

Date:

2016-04-01

Citation:

Joseph, S., Sahai, A. K., Chattopadhyay, R., Sharmila, S., Abhilash, S., Rajeevan, M., Mandal, R., Dey, A., Borah, N. \& Phani, R. (2016). Extremes in June rainfall during the Indian summer monsoons of 2013 and 2014: observational analysis and extended-range prediction. QUARTERLY JOURNAL OF THE ROYAL METEOROLOGICAL SOCIETY, 142 (696), pp.1276-1289. https://doi.org/10.1002/qj.2730.

Persistent Link:

http://hdl.handle.net/11343/290931 